\title{
The role of $\mathrm{CO}^{*}$ as a spectator in $\mathrm{CO} 2$ electro-reduction on $\mathrm{RuO} 2$
}

\author{
Bhowmik, Arghya; Hansen, Heine Anton; Vegge, Tejs
}

Published in:

The Journal of Physical Chemistry Part C

Link to article, DOI:

10.1021/acs.jpcc.7b04242

Publication date:

2017

Document Version

Peer reviewed version

Link back to DTU Orbit

Citation (APA):

Bhowmik, A., Hansen, H. A., \& Vegge, T. (2017). The role of $\mathrm{CO}^{*}$ as a spectator in $\mathrm{CO}_{2}$ electro-reduction on $\mathrm{RuO}_{2}$. The Journal of Physical Chemistry Part C, 121(34), 18333-18343.

https. $/ /$ /doi.org/10.1021/acs.jpcc.7b04242

\section{General rights}

Copyright and moral rights for the publications made accessible in the public portal are retained by the authors and/or other copyright owners and it is a condition of accessing publications that users recognise and abide by the legal requirements associated with these rights.

- Users may download and print one copy of any publication from the public portal for the purpose of private study or research.

- You may not further distribute the material or use it for any profit-making activity or commercial gain

- You may freely distribute the URL identifying the publication in the public portal

If you believe that this document breaches copyright please contact us providing details, and we will remove access to the work immediately and investigate your claim 
The role of $\mathrm{CO}^{*}$ as a spectator in $\mathrm{CO}$ electro-reduction on RuO

Arghya Bhowmik, Heine Anton Hansen, and Tejs Vegge

J. Phys. Chem. C, Just Accepted Manuscript • DOI: 10.1021/acs.jpcc.7b04242 • Publication Date (Web): 02 Aug 2017

Downloaded from http://pubs.acs.org on August 5, 2017

\section{Just Accepted}

"Just Accepted" manuscripts have been peer-reviewed and accepted for publication. They are posted online prior to technical editing, formatting for publication and author proofing. The American Chemical Society provides "Just Accepted" as a free service to the research community to expedite the dissemination of scientific material as soon as possible after acceptance. "Just Accepted" manuscripts appear in full in PDF format accompanied by an HTML abstract. "Just Accepted" manuscripts have been fully peer reviewed, but should not be considered the official version of record. They are accessible to all readers and citable by the Digital Object Identifier (DO|®). "Just Accepted" is an optional service offered to authors. Therefore, the "Just Accepted" Web site may not include all articles that will be published in the journal. After a manuscript is technically edited and formatted, it will be removed from the "Just Accepted" Web site and published as an ASAP article. Note that technical editing may introduce minor changes to the manuscript text and/or graphics which could affect content, and all legal disclaimers and ethical guidelines that apply to the journal pertain. ACS cannot be held responsible for errors or consequences arising from the use of information contained in these "Just Accepted" manuscripts. 


\title{
The Role of $\mathrm{CO}^{*}$ as a Spectator in $\mathrm{CO}_{2}$ Electro-reduction on $\mathrm{RuO}_{2}$
}

\author{
Arghya Bhowmik, Dr. Heine Anton Hansen and Prof. Dr. Tejs Vegge* \\ Department of Energy Conversion and Storage, Technical University of Denmark, \\ Fysikvej Bldg. 309, \\ DK-2800 Kgs. Lyngby, Denmark. \\ E-mail: teve@dtu.dk; Fax: +45 467757 58; Tel: +45 45258201
}

\begin{abstract}
:
$\mathrm{RuO}_{2}$ based electrocatalysts are found to be active at low over-potential towards direct electrochemical reduction of $\mathrm{CO}_{2}$ to formic acid and methanol. $\mathrm{RuO}_{2}$ can circumvent the thermodynamic bottleneck resulting from the scaling relations observed on metallic electrocatalyst, by employing an alternate pathway through oxygen-coordinated intermediates. Employing density functional theory based computational electrocatalysis models we show adsorbate-adsorbate interaction effects for adsorbates and reaction intermediates on the $\mathrm{RuO}_{2}(110)$ surface are large and impactful to the reaction thermodynamics. We studied binding energy amendment due to adsorbate interaction (steric and electronic) with varying coverage of $\mathrm{CO}^{*}$ spectators on the catalyst surface. Implications on the reaction pathways help us rationalize differences in experimentally observed carbonaceous product mix and suppression of the hydrogen evolution reaction (HER). We show that a moderate $\mathrm{CO}^{*}$ coverage $(\sim 50 \%)$ is necessary for obtaining methanol as a product and that higher $\mathrm{CO}^{*}$ coverages leads to very low overpotential for formic acid evolution. Our analysis also clarifies the importance of the reaction condition for $\mathrm{CO}_{2}$ reduction to liquid fuels utilizing $\mathrm{RuO}_{2}$ based electrocatalysts.
\end{abstract}

\section{Introduction}

The last hundred years of relentless human development have relied on fossil fuel based energy resources. To translate into a sustainable alternative course of long term growth ${ }^{1}$, expanding renewable energy resources must be tapped at the earliest possible time. This is to mitigate limitations of fossil fuel as well as the inherent environmental problems emanating from increased anthropogenic emissions of $\mathrm{CO}_{2}$. An electricity grid brimming with renewable electricity from wind and solar plants or 
cars propelled by renewable energy depends on inexpensive energy conversion and storage technologies ${ }^{2}$. Electrochemical reduction of carbon dioxide to liquid fuels is an appealing approach that could alleviate much of the $\mathrm{CO}_{2}$ emission challenge, solve the bottleneck of cheap energy storage and penetrate the fossil fuel dependent transport sector ${ }^{3}$. The main challenge of direct electrochemical reduction of $\mathrm{CO}_{2}$ to fuel molecules like formic acid, methanol or methane, is the absence of stable catalysts that can enable the $\mathrm{CO}_{2}$ reduction reaction (CO2RR) at low overpotential and high selectivity over the hydrogen evolution reaction $(\mathrm{HER})^{4,5}$. The underlying chemistry limiting the effectiveness of metallic catalysts in CO2RR to methane or methanol was recently ascertained through density functional theory based modeling of the thermodynamics of reaction steps involved ${ }^{6}$. Adsorbed $\mathrm{CO}\left(\mathrm{CO}^{*}\right)$ is a crucial reaction intermediate in the CO2RR pathway on metallic catalysts. Strong correlation between the binding energy of key intermediates $\mathrm{CO}^{*}$ and $\mathrm{CHO}^{*}$ on metal catalyst surfaces enforces a large potential requirement for CO2RR to methane irrespective of the $\mathrm{CO}^{*}$ binding energy of the metal ${ }^{7}$. Thus, further reduction of $\mathrm{CO}^{*}$ remains a bottleneck for metal catalysts. Only copper produces mixtures of methane, ethane and formic acid at high overpotential, owing to its favorable position in the theoretical activity volcano proposed in previous work. Ruthenium oxide based electrocatalysts have been repeatedly shown ${ }^{8-10}$ to produce methanol from $\mathrm{CO}_{2}$ with up to $60 \%$ Faradic Efficiency (FE) at low overpotential. Formic acid has been reported ${ }^{11}$ to be the other major $\mathrm{CO} 2 \mathrm{RR}$ product on $\mathrm{RuO}_{2}$ based electrocatalysts. While experimental results have been very affirmative towards good CO2RR activity, oxide catalysts have largely been overlooked amidst the recent spurt in scientific activity pertaining to electrocatalytic route to $\mathrm{CO}_{2}$ reduction ${ }^{12-18}$. Our previous work on $\mathrm{RuO}_{2}$-based electrocatalysts for $\mathrm{CO}_{2}$ reduction ${ }^{19}$ explained that a different reaction mechanism involving $\mathrm{HCOOH}^{*}$ intermediate instead of $\mathrm{CO}^{*}$ is active on oxide electrocatalysts. We have also established ${ }^{20}$ that different sets of scaling laws and resulting activity volcano leads to lower thermodynamic barriers for the $\mathrm{CO}_{2}$ conversion reaction than their metal counterparts. This behavior emanates from the fundamentally different reaction path followed on oxide catalysts compared to metal catalysts. $\mathrm{CO}_{2}$ activation on metals lead to $\mathrm{COOH}^{*}$ intermediate and consecutive protonation to reaction intermediates like $\mathrm{CO}^{*}, \mathrm{CHO}^{*} / \mathrm{COH}^{*}, \mathrm{CHOH}^{*} / \mathrm{H}_{2} \mathrm{CO}^{*}$ which tend to bind to the metal through the carbon atom ${ }^{21,22}$. On $\mathrm{RuO}_{2}(110), \mathrm{CO}_{2}$ activation leads to OCHO${ }^{*}$, which is further reduced to $\mathrm{HCOOH}^{*}, \mathrm{H} 2 \mathrm{COOH}$ etc, which bind to the catalyst through oxygen atoms ${ }^{19}$. The different reaction pathway signify different scaling relations govern CO2RR on oxide surfaces ${ }^{20}$. In particular, the limitation from the $\mathrm{CO} / \mathrm{CHO}$ * scaling is avoided.

The presence of spectator species on the catalyst surface can enhance or poison electrocatalyst activity, as have been studied theoretically and experimentally ${ }^{23-27}$. Despite the $\mathrm{COOH}^{*}$ intermediate being much less stable than the $\mathrm{OCHO}^{*}$ intermediate, a small amount of $\mathrm{COOH}^{*}$ might form on $\mathrm{CO}_{2}$ activation. Further 
reduction is expected to leave adsorbed $\mathrm{CO}^{*}$ from this contingent reaction ${ }^{11}$. $\mathrm{CO}^{*}$ spectators interact with other adsorbed reaction intermediates and alter their binding energy. We have observed that spectator $\mathrm{CO}^{*}$ species can have large effect on $\mathrm{H}^{*}$ binding free energy, potentially promoting/poisoning $\mathrm{HER}^{20}$. Similar behavior has been observed for metallic catalysts ${ }^{28}$. We expect similar effect can be present for $\mathrm{OH}^{*}$ binding free energy as well. Intermediates formed during CO2RR to methanol on the $\mathrm{RuO}_{2}$ catalyst surface are bound to the surface by oxygen atoms, and their binding energy is correlated with the $\mathrm{OH}^{*}$ binding energy. Thus a strong effect of $\mathrm{CO}^{*}$ spectators on the onset potential for methanol production and selectivity over HER is expected. Shift in the reaction site of CO2RR due to blockade of more favorable sites by $\mathrm{CO}^{*}$ spectator can have very large effect on the thermodynamics of elementary reaction steps. For example, under reducing conditions the $\mathrm{RuO}_{2}(110)$ surface can have both strong biding bridge sites and weak binding coordinated unsaturated (cus) sites available for intermediates. If all bridge sites (br) are occupied by spectator $\mathrm{CO}^{*}$ species, then the reaction can only proceed through cus sites. To create a categorical understanding of $\mathrm{CO}^{*}$ spectators on the CO2RR pathway on $\mathrm{RuO}_{2}(110)$ surface, we study the possible reaction intermediate and paths to formic acid, methanol and methane in the presence of different concentrations of $\mathrm{CO}^{*}$ spectators as well as variation in the br/cus sites occupied by spectator $\mathrm{CO}^{*}$. This work displays that weakening and strengthening of binding energies is of surprising importance towards both onset potential and possibly also the product selectivity for $\mathrm{CO} 2 \mathrm{RR}$ on $\mathrm{RuO}_{2}$. The outcome from this study is especially important to the understanding and development of oxide-based $\mathrm{CO}_{2} \mathrm{RR}$ electrocatalyst, which may break the scaling relations. We show that high $\mathrm{CO}^{*}$ coverage can render $\mathrm{RuO}_{2}$ based catalysts very effective at formic acid evolution and lower selectivity towards HER, while a moderate coverage improves on methanol selectivity. Our results might give a clue to the widely varied product composition obtained from CO2RR with $\mathrm{RuO}_{2}$ based electrocatalysts and highlight the importance of spectator coverage for successful CO2RR using $\mathrm{RuO}_{2}$.

\section{Computational details}

We utilize $\mathrm{VASP}^{29}$ package for density functional theory (DFT) based simulation of model catalyst surfaces with adsorbed reaction intermediates. Standard PBE-PAW potentials as distributed with VASP 5.3 are used with $500 \mathrm{eV}$ wavefunction cutoff. Previous comparison study on convergence of chemisorption energy on $\mathrm{RuO}_{2}$ surface from VASP (PAW) and Wien2K (all electron) indicated that $400 \mathrm{eV}$ cutoff is sufficient for routine calculations. $600 \mathrm{eV}$ cutoff for standard PAW can provide accuracy of up to $10 \mathrm{meV}^{30}$. Higher energy cutoff for this work is irrelevant as errors in the order of $0.1 \mathrm{eV}$ is expected in GGA level theory ${ }^{31}$. Here newly developed BEEF-vdW ${ }^{32}$ exchange correlation functional is utilized. Our lattice parameter estimates are $\mathrm{a}=4.537 \AA$ and $\mathrm{c}=3.135 \AA$ for $\mathrm{RuO}_{2}$, which agrees well with experimental data ${ }^{33}$. Following our previous studies ${ }^{19,20}$ the supercell representing 
the catalyst surface $\mathrm{RuO}_{2}(110)$ consists of a four layer thick slab with lower two layers fixed at atomic positions identical to bulk $\mathrm{RuO}_{2}$. The bridge site is considered vacant due to reducing environment during CO2RR (Figure SI1). This model has two bridge and two cus sites available for reaction intermediates and spectator $\mathrm{CO}^{*}$ molecules. During simulation, we use a 4x4x1 k-point mesh and $16 \AA$ of vacuum in the z-direction and Gaussian electronic smearing. Optimization of atomic positions are done until forces on atoms in top two layers and adsorbates are lower than 0.003 eVIÅ. Vibrational modes for adsorbed molecules are also analyzed to enable finite temperature free energy estimates by approximating adsorbate degrees of freedom as independent quantum mechanical harmonic oscillators (Table SI1). Adsorbate binding free energies are estimated w.r.t. gas phase free energies (Table $\mathrm{SI} 2)$ of hydrogen, water and $\mathrm{CO}_{2}{ }^{20}$. Systematic DFT-errors in total energy evaluation are corrected for $\mathrm{H}_{2}(0.1 \mathrm{eV}), \mathrm{CO}_{2}(0.3 \mathrm{eV})$, formic acid $(0.15 \mathrm{eV})$ and $\mathrm{COOH}^{*}(0.15$ $\mathrm{eV}$ ) following the approach by Christensen et al. ${ }^{34}$. A stabilization of formic acid in solution ${ }^{35}$ from deprotonation in neutral electrolyte $(-0.19 \mathrm{eV})$ is also taken into account, and the experimentally observed reaction product concentrations were used for free energy estimation of methanol ${ }^{9}$, formic acid and methane ${ }^{11}$ free energies. The reaction thermodynamics calculations are susceptible to variation in reactant/product concentration in the electrolyte. High concentration of methanol in electrolyte leads to increased free energy (up to $0.2 \mathrm{eV}$ ) and release of methanol might become difficult. The low vapor pressure of formic acid means small variation in free energy from higher concentration. Thus, effects of concentration are minimal for formic acid evolution.

Vibrational modes of adsorbate molecules are used to estimate zero-point energy, heat capacity and entropic contributions to the free energy at room temperature using the harmonic oscillator model as implemented in atomistic simulation environment (ASE). Usage of the reversible hydrogen electrode (RHE) scale for electrochemical potential helps simplify onset potential estimation by considering reversible formation of a proton/electron pair from a hydrogen molecule as zero $\mathrm{V}$ $\mathrm{RHE}$ at any given $\mathrm{pH}$. Accordingly, the analysis becomes $\mathrm{pH}$ independent except for the free energy of formic acid in solution. We have employed the computational hydrogen electrode ( $\mathrm{CHE}$ ) model ${ }^{36}$ to determine the thermodynamics of the electrochemical reaction steps involving single electron/proton transfer. The free energy of an adsorbate formed at the $n^{\text {th }}$ proton transfer step if lowered by $n \mathrm{U} e \mathrm{~V}$ when a potential of $U$ vs. RHE (V-RHE) is applied. Under the assumptions of the CHE model, for a particular, elementary proton transfer step, requiring an increase in binding free energy can be made free energy neutral by applying a negative potential, equivalent to the increase in free energy at $0 \mathrm{~V}-\mathrm{RHE}$. Hence, an analysis of relative binding energies of adsorbates formed at different electron transfer steps (Table 1) at $0 \mathrm{~V}$-RHE allows us to investigate modifications in CO2RR pathway and onset potential as well as selectivity over HER due to adsorbate interactions with $\mathrm{CO}^{*}$. 
Table 1: Adsorbate/product cases examined at electron transfer step from $0 e^{-}$to $8 e^{-}$

\begin{tabular}{|l|l|l|l|l|}
\hline $0 \mathrm{e}^{-}$ & $1 \mathrm{e}^{-}$ & $2 \mathrm{e}^{-}$ & $3 \mathrm{e}^{-}$ & $4 \mathrm{e}^{-}$ \\
\hline & $\begin{array}{l}\mathrm{OCHO}^{*}, \\
\mathrm{H}^{*}, \\
\mathrm{COOH}^{*}\end{array}$ & $\begin{array}{l}\mathrm{COOH}^{*}, \\
\mathrm{CO}^{*}+\mathrm{H}_{2} \mathrm{O}(\mathrm{I}), \\
\mathrm{HCOOH}(\mathrm{aq}), \\
\mathrm{H}_{2}(\mathrm{aq})\end{array}$ & $\begin{array}{l}\mathrm{H}_{2} \mathrm{COOH}^{*} \\
7 \mathrm{e}^{-}\end{array}$ & $\begin{array}{l}\mathrm{H}_{3} \mathrm{CO}^{*}+\mathrm{OH}^{*}, \\
\mathrm{H}_{2} \mathrm{CO}+\mathrm{H}_{2} \mathrm{O}(\mathrm{I}), \\
\mathrm{O}^{*}+\mathrm{CH}_{3} \mathrm{OH}(\mathrm{aq})\end{array}$ \\
\hline $5 \mathrm{e}^{-}$ & $6 \mathrm{e}^{-}$ & $8 \mathrm{e}^{-}$ & \\
\hline $\begin{array}{l}\mathrm{H}_{3} \mathrm{CO}^{*}+\mathrm{H}_{2} \mathrm{O}(\mathrm{I}), \\
\mathrm{H}_{2} \mathrm{COH}^{*}+\mathrm{H}_{2} \mathrm{O}(\mathrm{I}), \\
\mathrm{OH}^{*}+\mathrm{CH}_{3} \mathrm{OH}(\mathrm{aq})\end{array}$ & $\begin{array}{l}\mathrm{O}^{*}+\mathrm{CH}_{4}(\mathrm{aq})+ \\
\mathrm{H}_{2} \mathrm{O}(\mathrm{I}), \\
\mathrm{CH}_{3} \mathrm{OH}+\mathrm{H}_{2} \mathrm{O}(\mathrm{I}), \\
\mathrm{CH}_{3} \mathrm{OH}(\mathrm{aq})+\mathrm{CH}_{2} \mathrm{O}(\mathrm{I})\end{array}$ & $\begin{array}{l}+\mathrm{H}_{2} \mathrm{O}(\mathrm{I}) \\
\mathrm{CH}_{4}(\mathrm{aq})+ \\
\mathrm{H}_{2} \mathrm{O}(\mathrm{I})\end{array}$ & \\
\hline
\end{tabular}

\section{Results and discussion}

\subsection{Spectator coverage}

With four adsorption sites in the simulation model (Figure SI1), CO* coverage can be $0 \%, 25 \%, 50 \%, 75 \%$ or $100 \%$, respectively. Each $\mathrm{CO}^{*}$ spectator in the simulation model amounts to $25 \%$ added $\mathrm{CO}^{*}$ coverage. With full $\mathrm{CO}^{*}$ coverage, CO2RR or HER cannot advance due to unavailability of active sites, unless $\mathrm{CO}^{*}$ is first reduced. Two different types of active site being present and considering symmetry of the relative positions of the $\mathrm{CO}^{*}$ adsorbates, $25 \%$ and $75 \%$ coverage can be realized in two different ways, while $50 \%$ coverage leads to four different representations (Figure SI2). All such different $\mathrm{CO}^{*}$ coverages are inspected for their relative thermodynamic stability (Figure SI3). Visual representations are provided in Figure $\mathrm{SI} 2$.

On the bare surface, the $1 \mathrm{st} \mathrm{CO}^{*}$ adsorption at the bridge site is favorable compared to cus site by $0.18 \mathrm{eV}$ (Figure SI3). With respect to the $\mathrm{CO}$ molecule, the binding free energy of $\mathrm{CO}^{*}$ at the bridge site of the bare surfaces is $-1.34 \mathrm{eV}$. Two cus sites and one bridge site are accessible for catalysis at $25 \% \mathrm{CO}^{*}$ coverage. With $50 \% \mathrm{CO}^{*}$ coverage, putting all adsorbates in the bridge site is the most stable configuration. All other cus configurations with $50 \% \mathrm{CO}^{*}$ coverage are less stable by $0.28 \mathrm{eV}$. The adsorption free energy for the two $50 \% \mathrm{CO}^{*}$ coverage configurations with a combination of bridge and cus occupancy are less stable than the all bridge configuration by $0.08 \mathrm{eV}$ (while neighboring bridge and cus sites have $\mathrm{CO}^{*}$ (bridge+cus-near in SI3)) and $0.1 \mathrm{eV}$ (occupied bridge and cus sites are far apart (bridge+cus-far in SI3)). With both bridge sites covered by $\mathrm{CO}^{*}$, catalysis can only occur on the cus sites available (Figure SI2). On the other hand, if $\mathrm{CO}$ at $50 \% \mathrm{CO}^{*}$ coverage occupies both bridge and cus sites, there are still bridge and cus sites available for $\mathrm{CO} 2 \mathrm{RR}$. At $75 \% \mathrm{CO}^{*}$ coverage, the adsorbate configuration with $\mathrm{CO}^{*}$ 
on $2^{*}$ bridge+cus sites is more stable than $\mathrm{CO}^{*}$ on bridge $+2^{*}$ cus by $0.2 \mathrm{eV}$ (Figure SI3). These two configurations are fundamentally different, as the first allows catalysis through the cus sites and the latter requires the reaction to take place at the bridge site (Figure SI2). Due to repulsive $\mathrm{CO}^{*}-\mathrm{CO}^{*}$ interactions, the incremental binding free energy for $\mathrm{CO}^{*}$ decreases with $\mathrm{CO}^{*}$ coverage (Figure $\mathrm{SI} 3$ ). The incremental binding free energy for four $\mathrm{CO}^{*}$ molecules considering the most stable configurations are $-1.34 \mathrm{eV},-0.93 \mathrm{eV},-0.75 \mathrm{eV}$, and $-0.46 \mathrm{eV}$, respectively. Thus the driving force for further $\mathrm{CO}^{*}$ adsorption is smaller at high $\mathrm{CO}^{*}$ coverage. It is striking that at $0 \mathrm{~V}-\mathrm{RHE}$ and $75 \% \mathrm{CO}^{*}$ coverage, $\mathrm{OH}^{*}$ binds slightly stronger to the empty fourth site than $\mathrm{CO}^{*}$ (by $0.02 \mathrm{eV}$ ). Thus $\mathrm{OH}^{*}$ can displace the $4^{\text {th }} \mathrm{CO}^{*}$.

The $\mathrm{CO}^{*}$ spectator coverage at experimental conditions can also be limited due to reduction of $\mathrm{CO}^{*}$ to $\mathrm{CHO}^{*}$ or $\mathrm{COH}^{*}$, lowering the $\mathrm{CO}^{*}$ coverage. $\mathrm{CHO}^{*}$ is more stable than $\mathrm{COH}^{*}$ on the $\mathrm{RuO}_{2}(110)$ surface by $0.22 \mathrm{eV}$ to $0.45 \mathrm{eV}$ for different $\mathrm{CO}^{*}$ coverages. At $0 \mathrm{~V}$-RHE, the reduction of one of $\mathrm{CO}^{*}$ to $\mathrm{CHO}^{*}$ is energetically uphill by $1.34 \mathrm{eV}, 0.63 \mathrm{eV}, 0.73 \mathrm{eV}$, and $0.03 \mathrm{eV}$ for $\mathrm{CO}^{*}$ coverage of $25 \%, 50 \%, 75 \%$, and $100 \%$, respectively. This indicates, that complete poisoning of the catalyst surfaces is not favorable. On the contrary, $\mathrm{CO}^{*}$ spectators will not be removed by reduction even with application of moderate reducing potential if the coverage is low ( $25 \%)$. $50 \%$ and $75 \% \mathrm{CO}^{*}$ coverage might be observed under CO2RR conditions, due to kinetic barriers of $\mathrm{CO}^{*}$ protonation and transient evolution of $\mathrm{CO}$ from CO2RR. Slow transport of $\mathrm{CO}$ away from the catalyst will eventually leave the catalyst surface with high $\mathrm{CO}^{*}$ coverage $^{37}$ as might be the case in a previous experimental study ${ }^{11}$.

Previous studies by Popic et al. and $\mathrm{Qu}$ et al. employing pure ruthenium oxide electrocatalyst ${ }^{9,10}$ have not reported any $\mathrm{CO}$ detected as a product. We deduce that these experimental results observing methanol as the primary product, might have a catalyst surface with low to medium $\mathrm{CO}^{*}$ coverage if only a very small quantity of $\mathrm{CO}$ is produced and stays bound to the active site ${ }^{9,10}$. On the contrary, experiments by Spataru et al. ${ }^{11}$ observe hydrogen and formic acid as dominant products along with methanol, methane and $\mathrm{CO}$. It can be contemplated that the presence of $\mathrm{CO}$ at 30 to $200 \mathrm{ppm}^{11}$ in the solution comes from CO escaping the catalyst surface when a high $\mathrm{CO}^{*}$ coverage is reached.

\subsection{Hydroxylation with $\mathrm{CO}^{*}$ spectator}

$\mathrm{CO}_{2}$ is often reduced in aqueous electrolytes. Hydroxylation of active sites is energetically downhill and spontaneous at the bridge site of $\mathrm{RuO}_{2}$ (110) surface (Figure 1). Any available bridge site is expected to be hydroxylated at $0 \mathrm{~V}-\mathrm{RHE}$. $\mathrm{OH}^{*}$ needs to be removed from the active site for CO2RR to proceed. Thus $\mathrm{OH}^{*}$ removal can become a thermodynamic limiting step. Interactions between $\mathrm{CO}^{*}$ and $\mathrm{OH}^{*}$ are attractive for $25 \%$ to $50 \% \mathrm{CO}^{*}$ coverage, making $\mathrm{OH}^{*}$ binding is stronger in presence of $\mathrm{CO}^{*}$ spectators (Figure 1 ). 


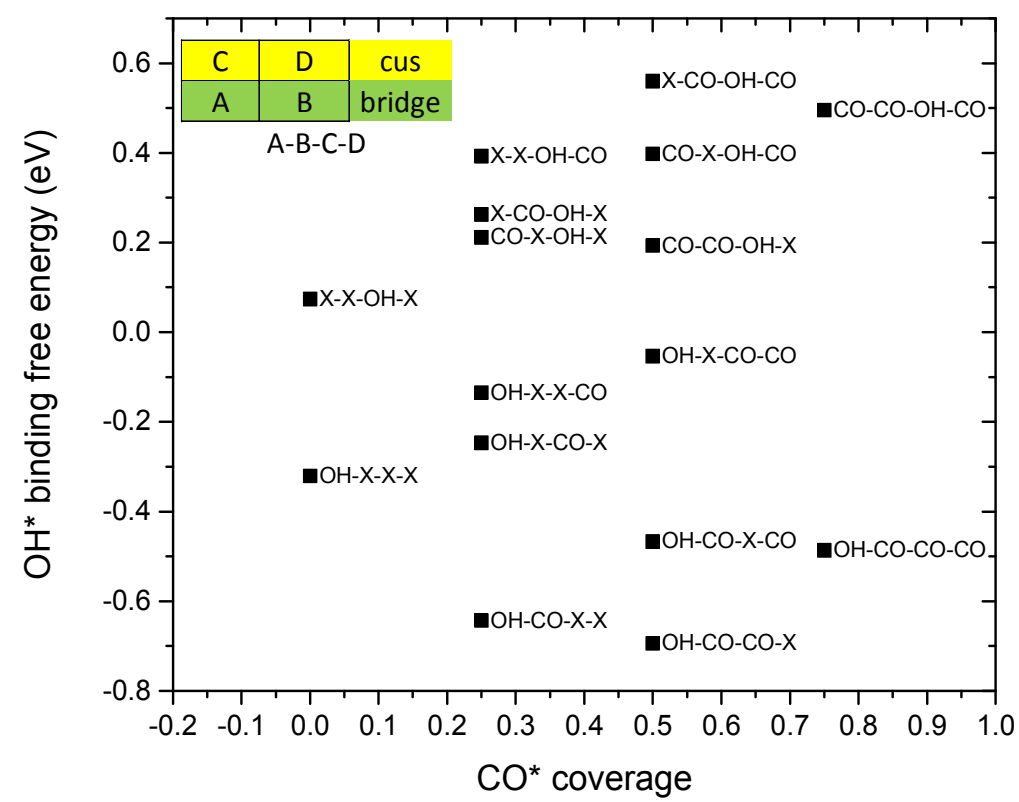

Figure 1: $\mathrm{OH}^{*}$ binding energy as a function of $\mathrm{CO}^{*}$ coverage and spatial distribution of $\mathrm{CO}^{*}$ adsorbates. As depicted in the inset, the distribution of $\mathrm{OH}^{*}$ and $\mathrm{CO}^{*}$ at the two bridge and two cus sites consecutively are used as label, where $X$ denotes an unoccupied site.

Investigations of the adsorbate binding free energy on the $\mathrm{RuO}_{2}(110)$ surface at bridge and cus sites reveal that oxygen coordinated adsorbates like $\mathrm{OH}^{*}$ bind significantly stronger to the bridge sites compared to cus sites (Figure 1). The relative preference for bridge sites is less pronounced for $\mathrm{CO}^{*}$ (Figure SI3). The binding energy for $\mathrm{OH}^{*}$ at different $\mathrm{CO}^{*}$ spectator configurations and binding sites are presented in Figure 1 showing favored bridge site binding of $\mathrm{OH}^{*}$ over cus site binding. For example, the binding energy of $\mathrm{OH}^{*}$ at bridge and cus sites are $-0.32 \mathrm{eV}$ and $+0.08 \mathrm{eV}$, respectively, while these values for $\mathrm{CO}^{*}$ is $-1.34 \mathrm{eV}$ and $-1.16 \mathrm{eV}$ (w.r.t. CO molecule). This observation helps to understand the distribution of spectating $\mathrm{CO}^{*}$ in bridge and cus sites under reaction conditions. Key CO2RR intermediates on oxide surfaces like $\mathrm{OCHO}^{*} / \mathrm{HCOOH}^{*} / \mathrm{H}_{2} \mathrm{COOH}^{*}$, etc., are all Ocoordinated. If a mixture of $\mathrm{CO}^{*}$ and $\mathrm{O}$-coordinated intermediates are present on the catalyst surface, CO2RR intermediates would preferentially occupy the bridge sites and the bi-dentate coordination will be preferred over mono-dentate binding. For example, three $\mathrm{CO}^{*}$ and one $\mathrm{OH}^{*}$ adsorbate can be distributed such that $\mathrm{OH}^{*}$ can occupy a bridge site or it can occupy a cus site. The configuration with $\mathrm{OH}^{*}$ in bridge site has $\sim 1 \mathrm{eV}$ lower free energy than the configuration with $\mathrm{OH}^{*}$ in cus site (Figure 1 ). This is critical in effective CO2RR catalysis on the $\mathrm{RuO}_{2}(110)$ surface. 
Reaction path thermodynamics shows that bridge site CO2RR is not only energetically preferred but also has lower thermodynamic onset potential. For example, at $75 \% \mathrm{CO}^{*}$ coverage, $\mathrm{OCHO}^{*}$ is unlikely to form the cus site (binding free energy of $+0.95 \mathrm{eV}$ ) but bridge site occupation as a mono-dentate adsorbate is feasible (binding free energy of $-0.13 \mathrm{eV}$. The preferred $\mathrm{CO}^{*}$ spectator configurations important for CO2RR at $0 \%, 25 \%, 50 \%, 75 \% \mathrm{CO}^{*}$ coverage are given in Figure 2 (a)-(d). Other free bridge sites and cus sites can be occupied by CO2RR/HER adsorbates as portrayed in Figure 2(e)-(i). $\mathrm{OCHO}^{*}$ and $\mathrm{H}_{2} \mathrm{COOH}^{*}$ adsorbate binds as bi-dentate adsorbate if adjoining bridge and cus sites are not occupied by $\mathrm{CO}^{*}$ spectators (Figure $2(\mathrm{e})$ and $(\mathrm{h})$ ). These adsorbates are mono-dentate at high $\mathrm{CO}^{*}$ coverage (Figure 2 (f)). Adsorbates like $\mathrm{H}_{2} \mathrm{CO}^{*}$ (Figure 2(j)) and $\mathrm{HCOOH}^{*}$ (Figure 2 (g)) are always mono-dentate but reaction intermediate can consist of a pair of adsorbate like $\mathrm{H}_{3} \mathrm{CO}^{*}+\mathrm{OH}^{*}$ (Figure 2(i)). The priority of O-atom coordinated CO2RR intermediates at bridge site is not valid for HER and HER can proceed even at cus site, while bridge sites are hydroxylated. Therefore, HER thermodynamic analysis is done for variety of spectators.

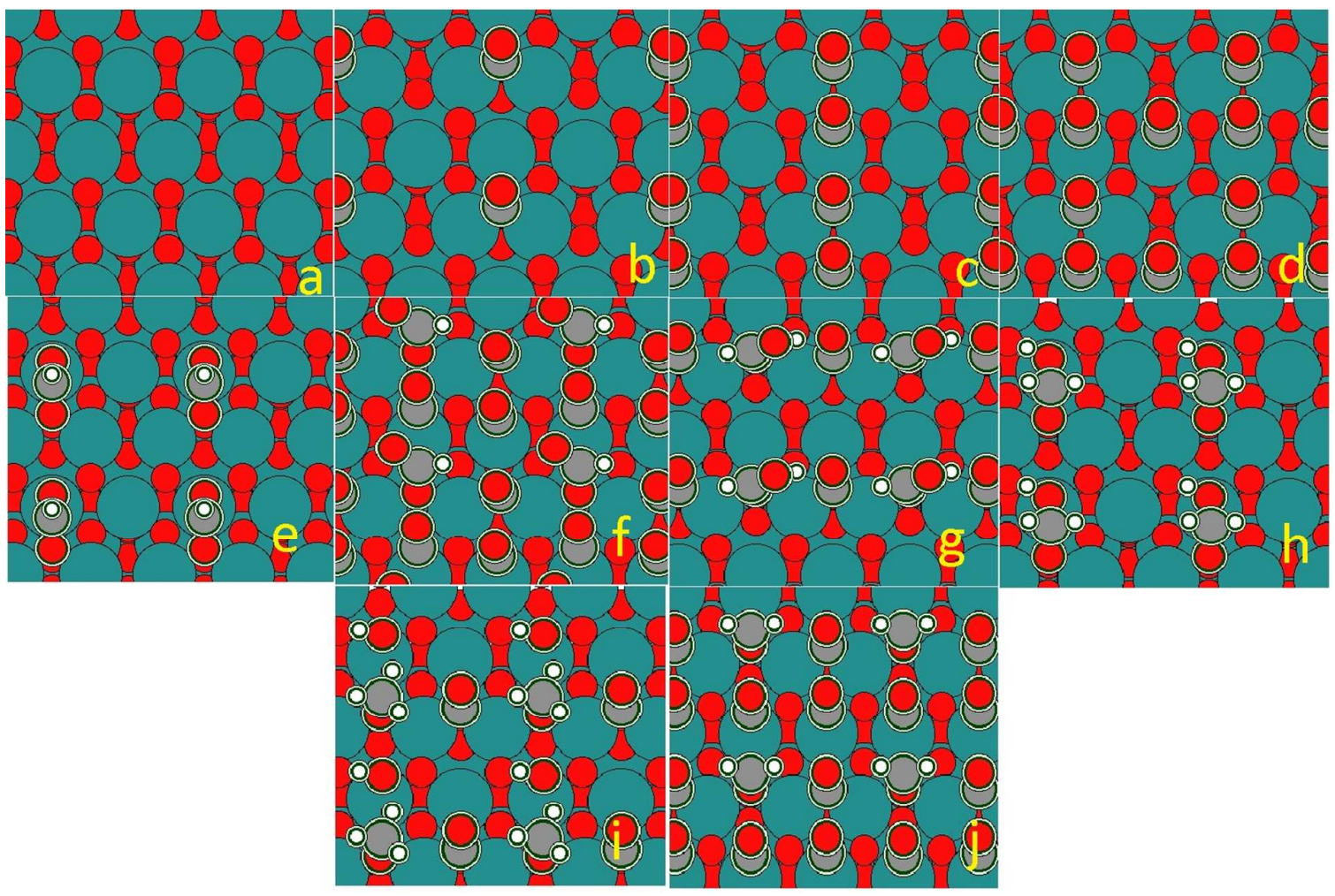

Figure 2: Simulated $\mathrm{RuO}_{2}(110)$ surface with two bridge sites and two cus sites available. Bridge sites are coordinated to two ruthenium atoms, and cus sites are on top of ruthenium atoms. (a) all sites empty. (b) one bridge site have $\mathrm{CO}^{*}$. (c) one bridge site and one cus site have $\mathrm{CO}^{*}$. (d) one bridge site and two cus sites have CO*. (e) bi-dentate OCHO* bound through one bridge and one cus site. (f) OCHO* in mono-dentate configuration in bridge site with three $\mathrm{CO}^{*}$ spectators occupying all 
other sites. (g) $\mathrm{HCOOH}^{*}$ at the bridge site with $\mathrm{CO}^{*}$ in the other bridge site. (h) $\mathrm{H}_{2} \mathrm{COOH}^{*}$ in bi-dentate configuration. (i) $\mathrm{H}_{3} \mathrm{CO}^{*}+\mathrm{OH}^{*}$ intermediate with one bridge site $\mathrm{CO}^{*}$ spectator (j) $\mathrm{H}_{2} \mathrm{CO}^{*}$ in bridge site with two cus site and one cus site CO* spectators. The actual unit cell in simulation is given in Figure SI1.

\section{3. $\mathrm{CO}_{2}$ activation: $\mathrm{OCHO}^{*}$ vs $\mathrm{COOH}^{*}$}

From a purely thermodynamic point of view, the free energy diagrams identifies which reaction intermediate is most favorable at a particular electron transfer step. For example, if $\mathrm{OCHO}^{*}$ is more stable than $\mathrm{COOH}^{*}$ at $0 \mathrm{~V}-\mathrm{RHE}$, it will remain the preferred intermediate at an applied reducing potential (Figure 3(a)). A proton transfer to $\mathrm{CO}_{2}$ molecules in the solvated phase creates both the intermediates. The free energy is lowered by the equal amount due to an applied reducing potential. $\mathrm{OCHO}^{*}$ is a bi-dentate adsorbate if adjacent sites are available. At $0 \%$ and $25 \% \mathrm{CO}^{*}$ coverage, $\mathrm{OCHO}^{*}$ binds through one bridge and one cus site (Figure 2(e)). Presence of $\mathrm{CO}^{*}$ in an adjacent bridge site strengthens the $\mathrm{OCHO}^{*}$ binding at low (25\%) $\mathrm{CO}^{*}$ coverage compared to bare catalyst surface (Figure 3(a)). At 50\% CO* coverage, $\mathrm{OCHO}^{*}$ can bind through one bridge and one cus site or through two cus sites depending upon the $\mathrm{CO}^{*}$ distribution. On a bare surface, $\mathrm{OCHO}^{*}$ occupying the bridge+cus sites have a binding free energy of $-0.81 \mathrm{eV}$. It is interesting to note that the configuration with bridge+cus distribution of $\mathrm{CO}^{*}$ spectators continue to be the more stable than bridge+bridge configuration when $\mathrm{OH}^{*}$ or $\mathrm{OCHO}^{*}$ are present on the surface. It can be argued that at a level of $50 \%$ coverage, CO2RR will occur through a combination of bridge and cus sites and $\mathrm{OCHO}^{*}$ stays bi-dentate. $75 \%$ $\mathrm{CO}^{*}$ coverage compel $\mathrm{OCHO}^{*}$ to be mono-dentate (Figure 2(f)), reducing the binding free energy significantly. Albeit, the $2^{*}$ cus+bridge configuration of $\mathrm{CO}^{*}$ adsorbates lets $\mathrm{OCHO}^{*}$ adsorb at the bridge site, which is significantly more favorable than the cus site adsorption. Thus, in the presence of $\mathrm{OCHO}^{*}$, the $2^{*}$ cus+bridge configuration of the $\mathrm{CO}^{*}$ spectators is more stable.

It should be noted that trends in $\mathrm{COOH}^{*}$ and $\mathrm{OCHO}^{*}$ binding free energy at different $\mathrm{CO}^{*}$ adsorbate configuration are similar and maintain their relative position in the free energy diagram. Figure 3(a) shows that $\mathrm{OCHO}^{*}$ intermediate is much stronger bound to the active site than $\mathrm{COOH}^{*}$, regardless of spectator coverage. Consequently, the $\mathrm{CO} 2 \mathrm{RR}$ pathway proceed preferentially through $\mathrm{OHCO}$ * and other $\mathrm{O}$-coordinated adsorbates at all $\mathrm{CO}^{*}$ coverages. The other (unwanted) intermediate after the $1^{\text {st }}$ proton transfer step is $\mathrm{H}^{*}$ (Figure $3(\mathrm{a})$ ). 


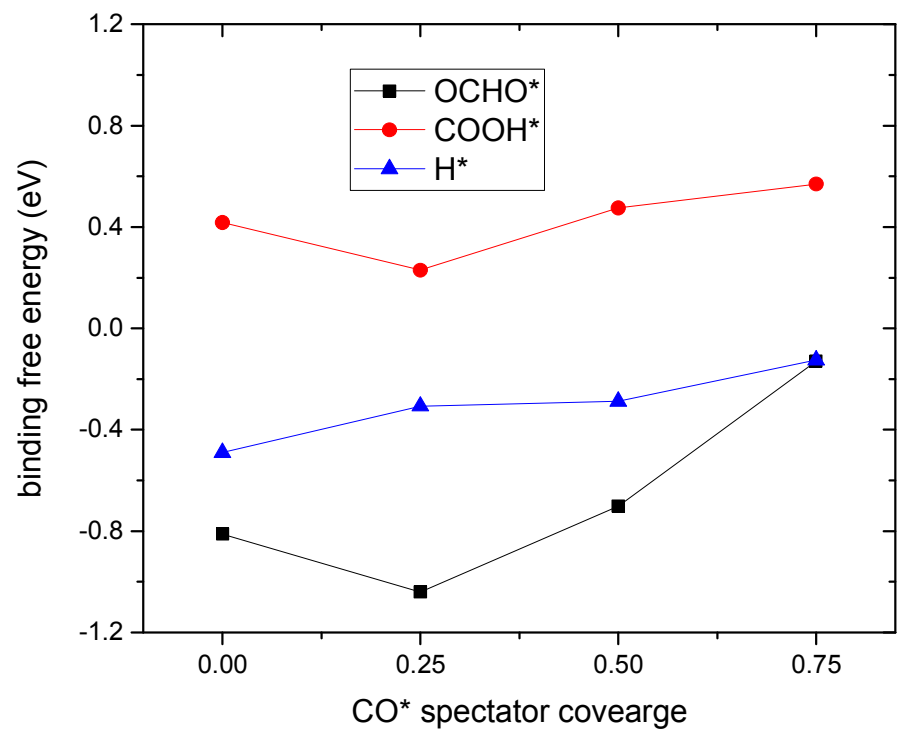

(a)

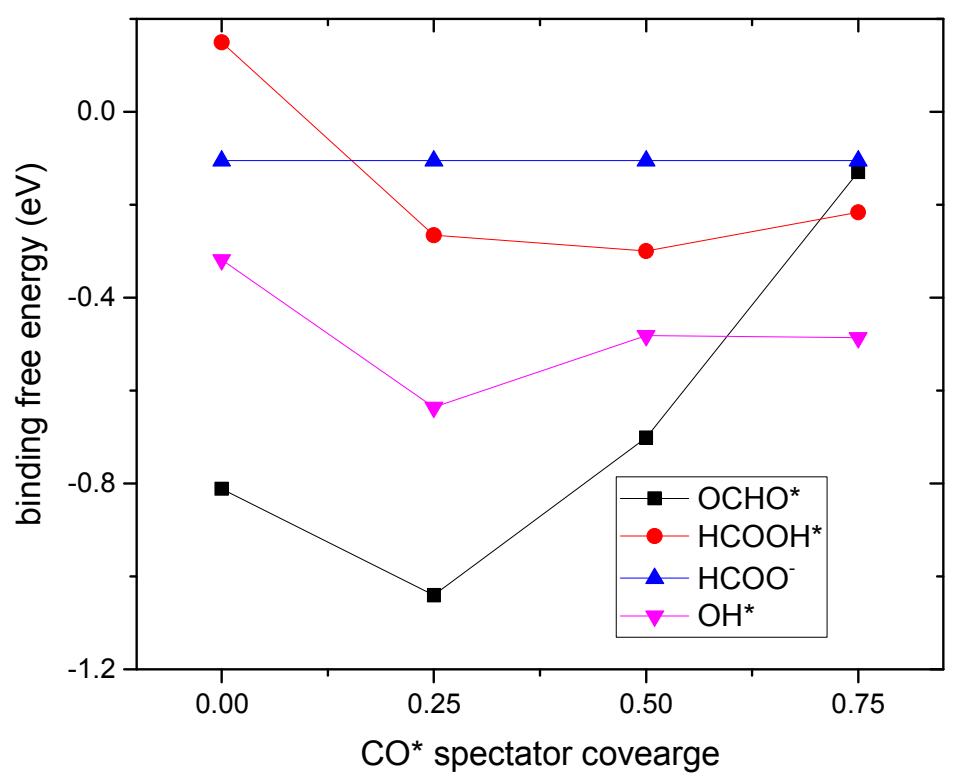

(b)

Figure 3: Effect of $\mathrm{CO}^{*}$ coverage on binding energy of (a) intermediates formed by the $1^{\text {st }}$ proton transfer*/OCHO*/COOH*; (b) $\mathrm{HCOOH}^{*}$ and $\mathrm{OH}^{*}$ at the available bridge site (or bridge+cus site for $\mathrm{OCHO}^{*}$ ) and free energy for deprotonated formic acid in solution. 


\subsection{Selectivity of CO2RR vs. HER}

The spectator adsorbate interaction between $\mathrm{CO}^{*}$ and $\mathrm{H}^{*}$ is repulsive and $\mathrm{H}^{*}$ binding weakens with higher $\mathrm{CO}^{*}$ coverage (Figure 3(a)). Substantially weaker binding of $\mathrm{H}^{*}$ than $\mathrm{OCHO}^{*}$ facilitate selectivity of $\mathrm{CO} 2 \mathrm{RR}$ over $\mathrm{HER}^{20}$. For $\mathrm{CO}^{*}$ coverages $0-50 \%$, $\mathrm{OCHO}^{*}$ is stronger bound to the catalyst surface than $\mathrm{H}^{*}$ by $0.31-0.73 \mathrm{eV}$ (Figure 2 (a)). The binding free energy difference is over $1 \mathrm{eV}$ for a coverage of $50 \% \mathrm{CO}^{*}$ occupying all the bridge sites (Figure SI4). Because $\mathrm{H}^{*}$ is a prerequisite for HER, we thus find the best selectivity for CO2RR at 50\% CO* coverage. For high $(75 \%) \mathrm{CO}^{*}$ coverage, owing to the aforementioned destabilization of $\mathrm{OCHO}^{*}, \mathrm{H}^{*}$ is equally probable to form (Figure 3(a)) at bridge sites (binding energy difference of $4 \mathrm{meV}$ between $\mathrm{H}^{*}$ and $\mathrm{OCHO}^{*}$ ). For $75 \%$ coverage and cus site adsorption, $\mathrm{H}^{*}$ is remarkably favored by $0.32 \mathrm{eV}$ over $\mathrm{OCHO}^{*}$ at cus sites (Figure SI5). At high $\mathrm{CO}^{*}$ coverage, $\mathrm{RuO}_{2}$ electrocatalysts should therefore show less selectivity towards CO2RR and evolve significant amounts of hydrogen.

$\mathrm{RuO}_{2}(110)$ bridge sites, when vacant, are hydroxylated in aqueous solution due to negative binding free energy of $\mathrm{OH}^{*}$ at the bridge site at $0 \mathrm{~V}-\mathrm{RHE}$ (Figure 1). Hydroxylation of cus sites is not energetically favorable at 0 V-RHE and HER can proceed at the cus site. For $0 \% \mathrm{CO}^{*}$ coverage and hydroxylated bridge sites, the $\mathrm{H}^{*}$ binding free energy at the cus site is $+0.33 \mathrm{eV}$, i.e. HER requires a reducing potential of $-0.33 \mathrm{~V}-\mathrm{RHE}$ (Table 2). However, the $\mathrm{OH}^{*}$ removal potential for clean $\mathrm{RuO}_{2}(110)$ surface bridge site is $-0.32 \mathrm{~V}$-RHE. Once $\mathrm{OH}^{*}$ is removed, on an otherwise empty surface, the $\mathrm{H}^{*}$ binding free energy at the cus site is $+0.22 \mathrm{eV} . \mathrm{H}^{*}$ binding at cus site (with $\mathrm{H}^{*}$ spectators at all bridge site) is $+0.41 \mathrm{eV}$. The surface coverage, onset potential and the reaction site might vary, but these binding free energies suggest that at very low $\mathrm{CO}^{*}$ coverage, only HER is active at reducing potential up to $-0.32 \mathrm{~V}$ RHE utilizing both bridge and cus sites. Schematics of few such spectator configurations (within the 2x2-model catalyst surface) for HER mechanism and predicted onset potentials are provided in Table 2. 
Table 2: Calculated thermodynamic onset potential [V-RHE] for HER at bridge and cus sites with different spectator species on $\mathrm{RuO}_{2}$ (110); yellow represents a cus site and green represents a bridge site. $\mathrm{OH}, \mathrm{CO}, \mathrm{H}$ are possible spectators and $\mathrm{X}$ is the absence of any of them. ${ }^{*}$ is the site considered for HER.

\begin{tabular}{|c|c|c|c|c|c|c|c|c|c|c|c|}
\hline \multicolumn{12}{|c|}{ Configurations } \\
\hline cus & $X$ & * & $\mathrm{CO}$ & ${ }^{*}$ & $X$ & * & $X$ & * & $\mathrm{CO}$ & * & \\
\hline bridge & $\mathrm{OH}$ & $\mathrm{OH}$ & $\mathrm{CO}$ & $\mathrm{OH}$ & $\mathrm{H}$ & $\mathrm{H}$ & $\mathrm{CO}$ & $x$ & $\mathrm{CO}$ & $\mathrm{X}$ & \\
\hline $\begin{array}{c}\text { HER } \\
\text { onset } \\
{[\mathrm{V}-\mathrm{RHE}]}\end{array}$ & \multicolumn{2}{|c|}{-0.33} & \multicolumn{2}{|c|}{-0.56} & \multicolumn{2}{|c|}{-0.41} & \multicolumn{2}{|c|}{-0.26} & \multicolumn{2}{|c|}{-0.22} & \\
\hline cus & $\mathrm{X}$ & ${ }^{*}$ & * & $x$ & $X$ & $X$ & $*$ & $X$ & $\mathrm{OH}$ & ${ }^{*}$ & \\
\hline Bridge & $\mathrm{OH}$ & $\mathrm{CO}$ & $\mathrm{X}$ & $\mathrm{X}$ & $\mathrm{CO}$ & * & $\mathrm{CO}$ & $\mathrm{CO}$ & $\mathrm{OH}$ & $\mathrm{OH}$ & \\
\hline $\begin{array}{c}\text { HER } \\
\text { onset } \\
{[\mathrm{V}-\mathrm{RHE}]}\end{array}$ & \multicolumn{2}{|c|}{-0.39} & \multicolumn{2}{|c|}{-0.22} & \multicolumn{2}{|c|}{-0.31} & \multicolumn{2}{|c|}{-0.41} & \multicolumn{2}{|c|}{-0.56} & \\
\hline cus & $x$ & $X$ & $\mathrm{CO}$ & $X$ & $\mathrm{CO}$ & ${ }^{*}$ & $\mathrm{CO}$ & $\mathrm{CO}$ & & & \\
\hline Bridge & * & $\mathrm{X}$ & $\mathrm{CO}$ & * & $\mathrm{CO}$ & $\mathrm{CO}$ & * & $\mathrm{CO}$ & & & \\
\hline $\begin{array}{c}\text { HER } \\
\text { onset } \\
{[\mathrm{V}-\mathrm{RHE}]}\end{array}$ & \multicolumn{2}{|c|}{-0.49} & \multicolumn{2}{|c|}{-0.29} & \multicolumn{2}{|c|}{-0.63} & \multicolumn{2}{|c|}{-0.13} & & & \\
\hline
\end{tabular}

Easy availability of $\mathrm{CO}_{2}$ in solution phase can prevent $\mathrm{HER}$ by formation of $\mathrm{OCHO}$ * in $2^{*}$ cus or bridge+cus bi-dentate configuration due to higher stability than $\mathrm{H}^{*}$ (Figure $3(\mathrm{a}))$. The binding free energy of $\mathrm{OCHO}^{*}$ in weak binding cus site $\left(2^{*} \mathrm{cus}\right.$ configuration) with bridge sites filled by $\mathrm{OH}^{*}$ is $-0.71 \mathrm{eV}$, and when bridge sites are filled with a mixture of $\mathrm{OH}^{*}$ and $\mathrm{CO}^{*}$, the $\mathrm{OCHO}^{*}$ binding free energy is $-0.70 \mathrm{eV}$. In comparison, $\mathrm{H}^{*}$ binding is $+0.33 \mathrm{eV}$ and $+0.39 \mathrm{eV}$ for similar bridge site spectator configuration, respectively.

For $25 \% \mathrm{CO}^{*}$ coverage, the attractive adsorbate-adsorbate interaction between $\mathrm{CO}^{*}$ and $\mathrm{OH}^{*}$ at bridge sites makes $\mathrm{OH}^{*}$ removal from bridge much more difficult $(-0.64$ $\mathrm{V}$-RHE). Again bi-dentate $\mathrm{OCHO}^{*}$ is very stable with a binding free energy of -1.04 $\mathrm{eV}$ at $25 \% \mathrm{CO}^{*}$ coverage. The $\mathrm{H}^{*}$ binding free energy at the cus site $\left(\mathrm{OH}^{*}\right.$ and $\mathrm{CO}^{*}$ being present at bridge sites) is $+0.39 \mathrm{eV}$, cancelling significant HER activity. A similar argument for subdued HER activity holds for $50 \% \mathrm{CO}^{*}$ coverage (all the bridge site occupied (Figure SI4)), where all cus sites are available for adsorption. $\mathrm{H}^{*}$ and $\mathrm{OCHO}^{*}$ have binding free energy of $+0.41 \mathrm{eV}$ and $-0.69 \mathrm{eV}$ respectively (Table SI4). On the other hand, in the more favorable configuration, the $\mathrm{CO}^{*}$ adsorbates are distributed between bridge and cus sites and the other bridge site is occupied by $\mathrm{OH}^{*} . \mathrm{H}^{*}$ binding free energy at the cus site is $+0.56 \mathrm{eV}$ but the bridge $\mathrm{OH}^{*}$ removal is estimated at $-0.48 \mathrm{~V}-\mathrm{RHE}$. $\mathrm{H}^{*}$ binding free energy at a free bridge site with $50 \% \mathrm{CO}^{*}$ coverage is $-0.29 \mathrm{eV}$ and that at cus site is $+0.26 \mathrm{eV}$. Consequently, HER can progress through bridge or cus sites at -0.3 V-RHE (Table 2) except when OCHO* forms occupying both the bridge and cus site. This analysis shows that up to $50 \%$ 
$\mathrm{CO}^{*}$ coverage is expected to allow little HER activity if $\mathrm{OCHO}^{*}$ forms rapidly. For the $2 *$ bridge+cus $\mathrm{CO}^{*}$ configuration $\left(75 \%\right.$ coverage), $\mathrm{H}^{*}$ binding is very weak $(+0.63 \mathrm{eV})$, while for $2^{*}$ cus +bridge configuration, $\mathrm{H}^{*}$ binding free energy is near ideal at $+0.03 \mathrm{eV}$ but hydroxylation of active site block HER above $-0.48 \mathrm{~V}-\mathrm{RHE}$.

\subsection{Impact of $\mathrm{CO}^{*}$ coverage on CO2RR intermediate binding}

Six of the $\mathrm{CO}^{*}$ coverage configurations (Figure SI2) are picked for analysis of the CO2RR reaction mechanism - 0\% CO* coverage, 25\% CO* coverage (bridge site), $50 \% \mathrm{CO}^{*}$ coverage (all bridge sites). 50\% CO* coverage (neighboring bridge and cus sites), $75 \% \quad \mathrm{CO}^{*}$ coverage (2*bridge+cus sites), $75 \% \mathrm{CO}^{*}$ coverage (bridge $+2^{*}$ cus sites). Multisite adsorbates like $\mathrm{H}_{3} \mathrm{CO}^{*}+\mathrm{OH}^{*}$, which occupy two bridge sites in absence of $\mathrm{CO}^{*}$ spectator and a combination of bridge+cus site for $25 \%$ and $50 \% \mathrm{CO}^{*}$ coverage. $75 \% \mathrm{CO}^{*}$ coverage only allows single site adsorbates. Some $\mathrm{CO} 2 \mathrm{RR}$ adsorbates like $\mathrm{OCHO}^{*}$ and $\mathrm{H}_{2} \mathrm{COOH}^{*}$ can attach to the catalyst surface through one or two active sites, due to the molecular geometry. Such bidentate adsorbates are allowed to remain so for $0-50 \% \mathrm{CO}^{*}$ coverage. Lack of multiple neighboring vacant active sites forces them to be mono-dentate at $75 \% \mathrm{CO}^{*}$ coverage.

A previous study has shown that binding free energy of O-atom coordinated CO2RR reaction intermediates scale with $\mathrm{OH}^{*}$ binding free energy on oxide catalysts surfaces ${ }^{20}$. Hence the strong spectator adsorbate interaction between $\mathrm{CO}^{*}$ and $\mathrm{OH}^{*}$ is expected to be valid for other O-atom coordinated CO2RR intermediates as well. Adsorbate binding energy diagrams at $0 \mathrm{~V}$-RHE (Figure 4) for $\mathrm{CO}^{*}$ configurations dominant at $0 \%, 25 \%$ (bridge site), $50 \%$ (bridge + cus sites) at $75 \%$ coverage (bridge $+2^{*}$ cus sites) are used to obtain key conclusions here. Reaction intermediate free energy diagrams with two other $\mathrm{CO}^{*}$ coverage configurations are provided in the supporting information (50\% coverage with all bridge sites occupied (Figure SI4) and $75 \%$ coverage with on cus site free (Figure SI5)). Binding energy of an adsorbate can change from both electronic interaction with spectators as well as modifications in adsorption geometry. 


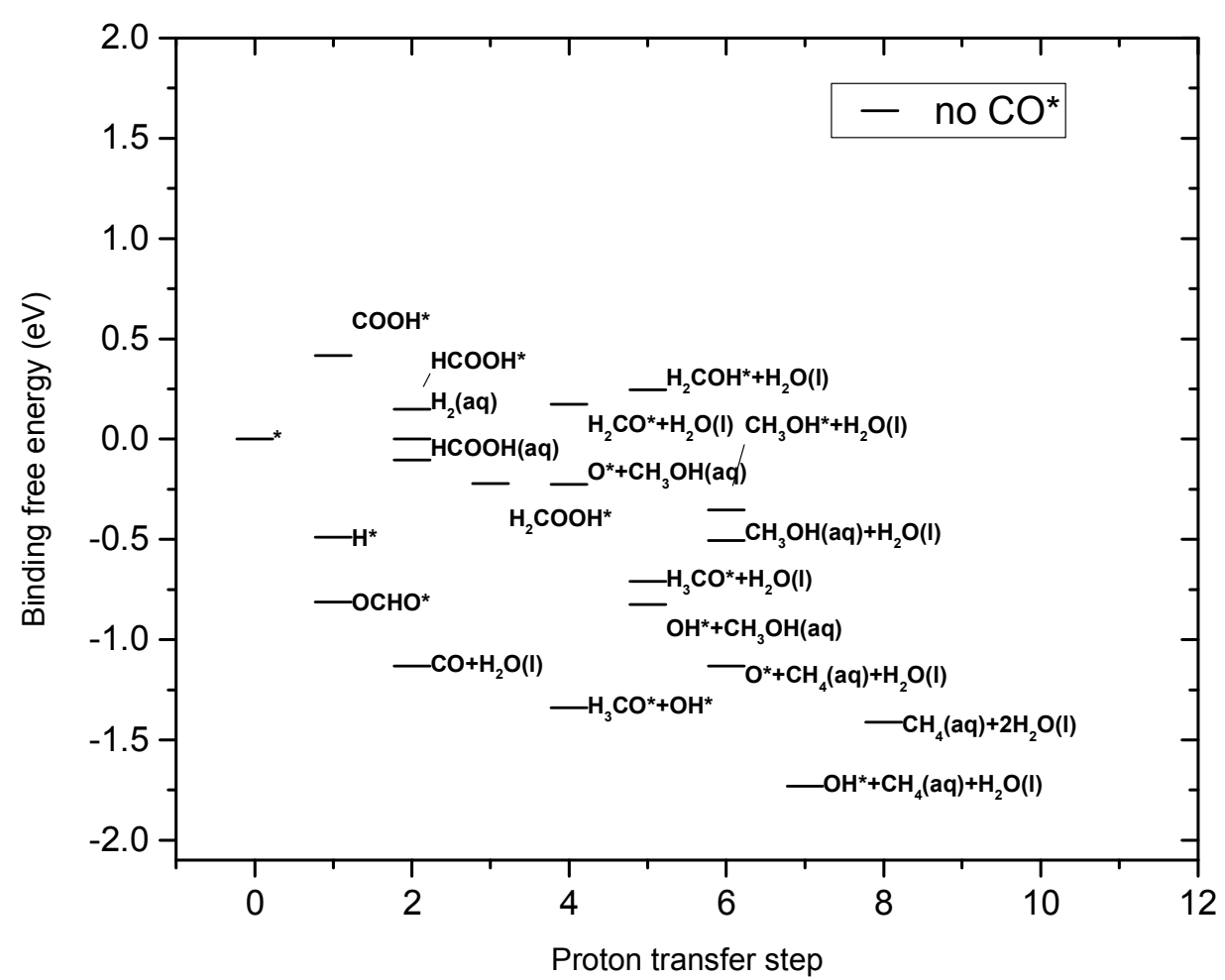

(a)

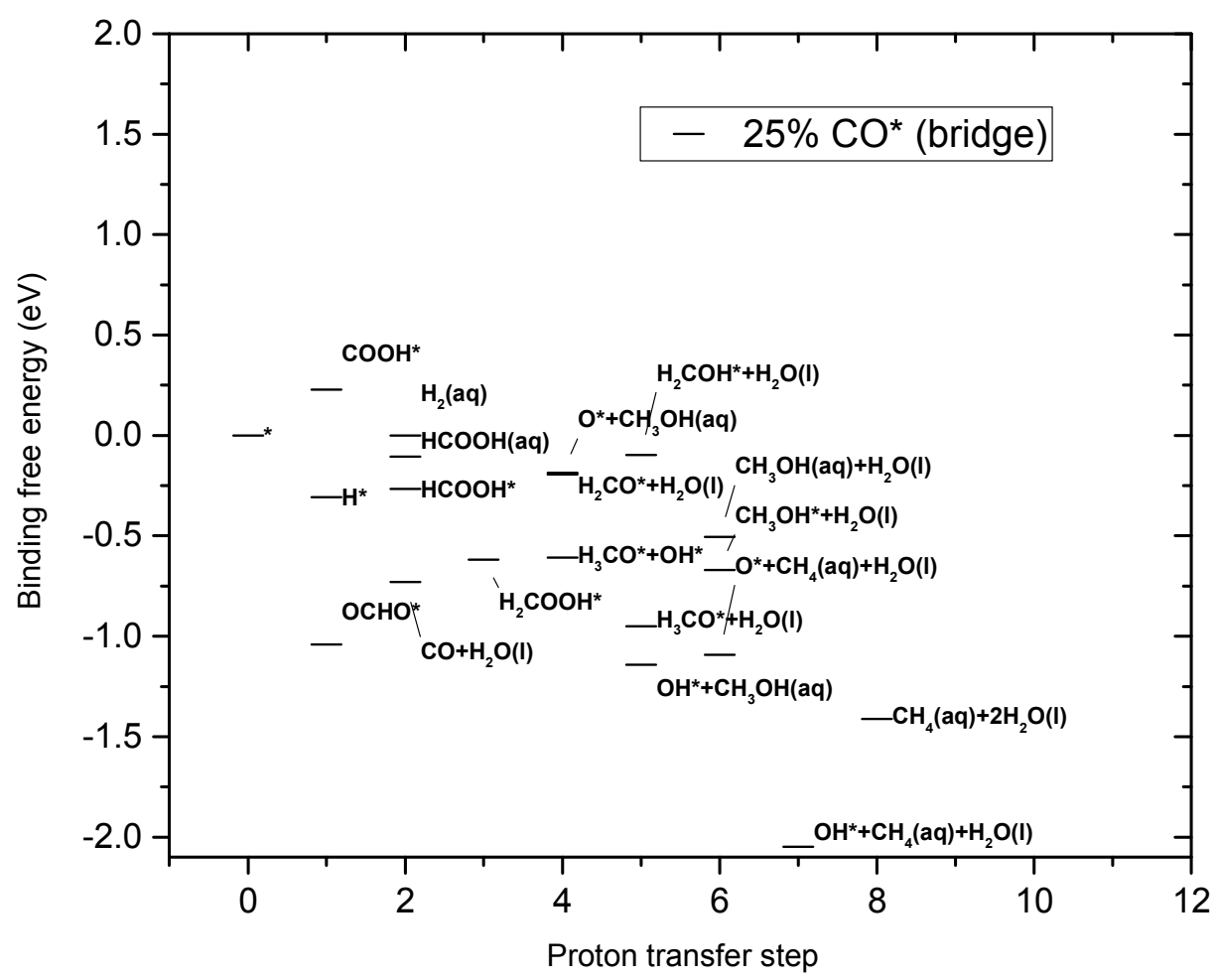

(b) 


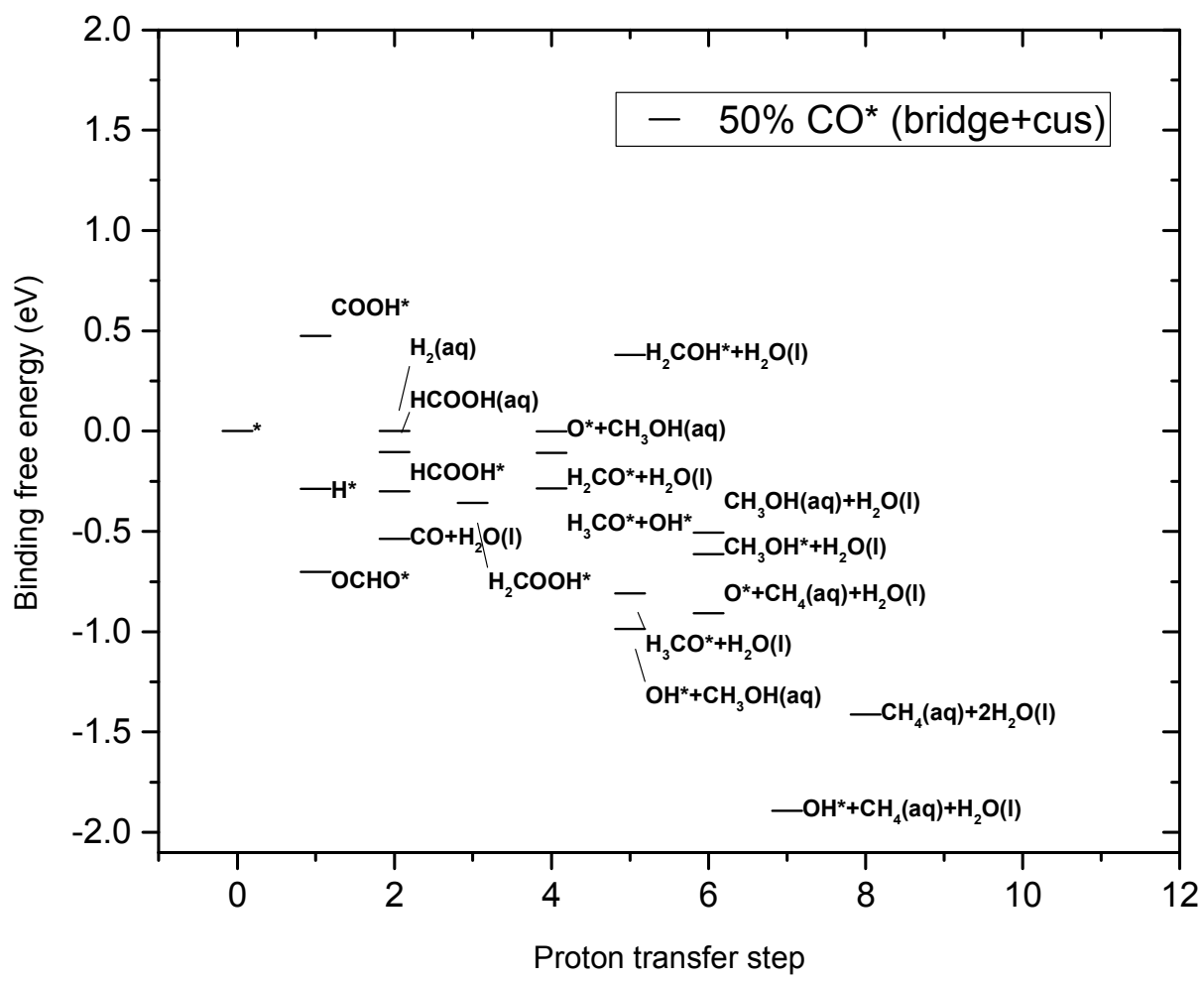

(c)

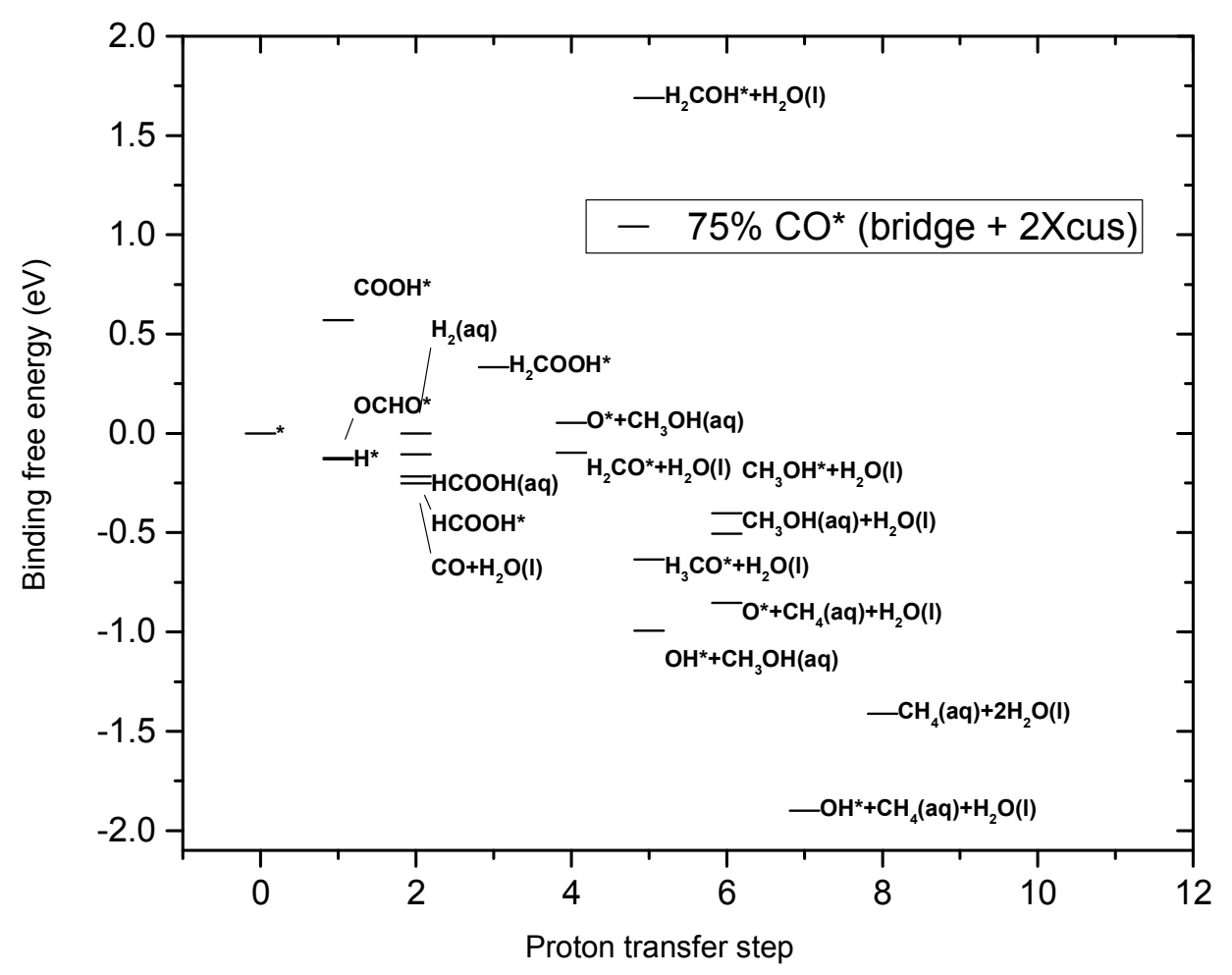

(d) 
Figure 4: Free energy diagram of possible reaction intermediates for HER/CO2RR at four different coverages of $\mathrm{CO}^{*}$ spectators - (a) $0 \%$ (b) $25 \%$ utilizing bridge sites (c) $50 \%$ utilizing half of bridge and cus sites (d) $75 \%$ utilizing all cus and half of bridge sites.. The sites occupied by spectator $\mathrm{CO}^{*}$ molecules are indicated. Adsorbate labels are on the right of the data point and adjusted in the $y$-direction to avoid superposition without changing the relative position between intermediates formed at the same electron transfer step.

\subsection{Impact of $\mathrm{CO}^{*}$ coverage on $\mathrm{CO} 2 \mathrm{RR}$}

The free energy diagram of reaction intermediates helps to identify which reaction intermediate is most favorable at a particular electron transfer step, and to determine the reaction mechanism. The $\mathrm{H}^{*} / \mathrm{OCHO}^{*}$ binding free energy correlation helps us understand the $\mathrm{HER} / \mathrm{CO} 2 \mathrm{RR}$ selectivity; the $\mathrm{HCOOH}^{*}$ binding free energy w.r.t solvated formic acid in solution (Figure 3(b)) dictates whether formic acid is the major product or higher proton transfer products like methanol is dominant. If the catalyst surface fails to bind formic acid molecules to the active site, it will escape into solution in a solvated form, rendering further hydrogenation difficult. $\mathrm{HCOOH}^{*}$ being $\mathrm{O}$-coordinated like $\mathrm{OH}^{*}$, the trend in the binding free energy variation at different $\mathrm{CO}^{*}$ coverage are similar for these adsorbates (Figure 3 (b)). Adsorbate-adsorbate interaction effects inducing stronger $\mathrm{OH}^{*}$ binding can open up the possibility of methanol/methane as product as seen in the case of partial $\mathrm{CO}^{*}$ coverage.

If the formic acid molecule fails to bind at the catalyst site, $\mathrm{H}_{2} \mathrm{COOH}^{*}$ is expected to form by application of an additional electrochemical driving force (equivalent to the stability of deprotonated and solvated formic acid compared to surface bound $\mathrm{HCOOH}^{*}$ ). However, the electrolyte needs to be saturated with formic acid to supply protonated formic acid molecules. Nevertheless, the accessibility requirement of solvated HCOO- and two protons close to the active site simultaneously suggests the kinetics will be extremely slow stopping further reduction. Absence of any $\mathrm{CO}^{*}$ coverage lead to release of formic acid in solution on hydrogenation of $\mathrm{OCHO}$. 


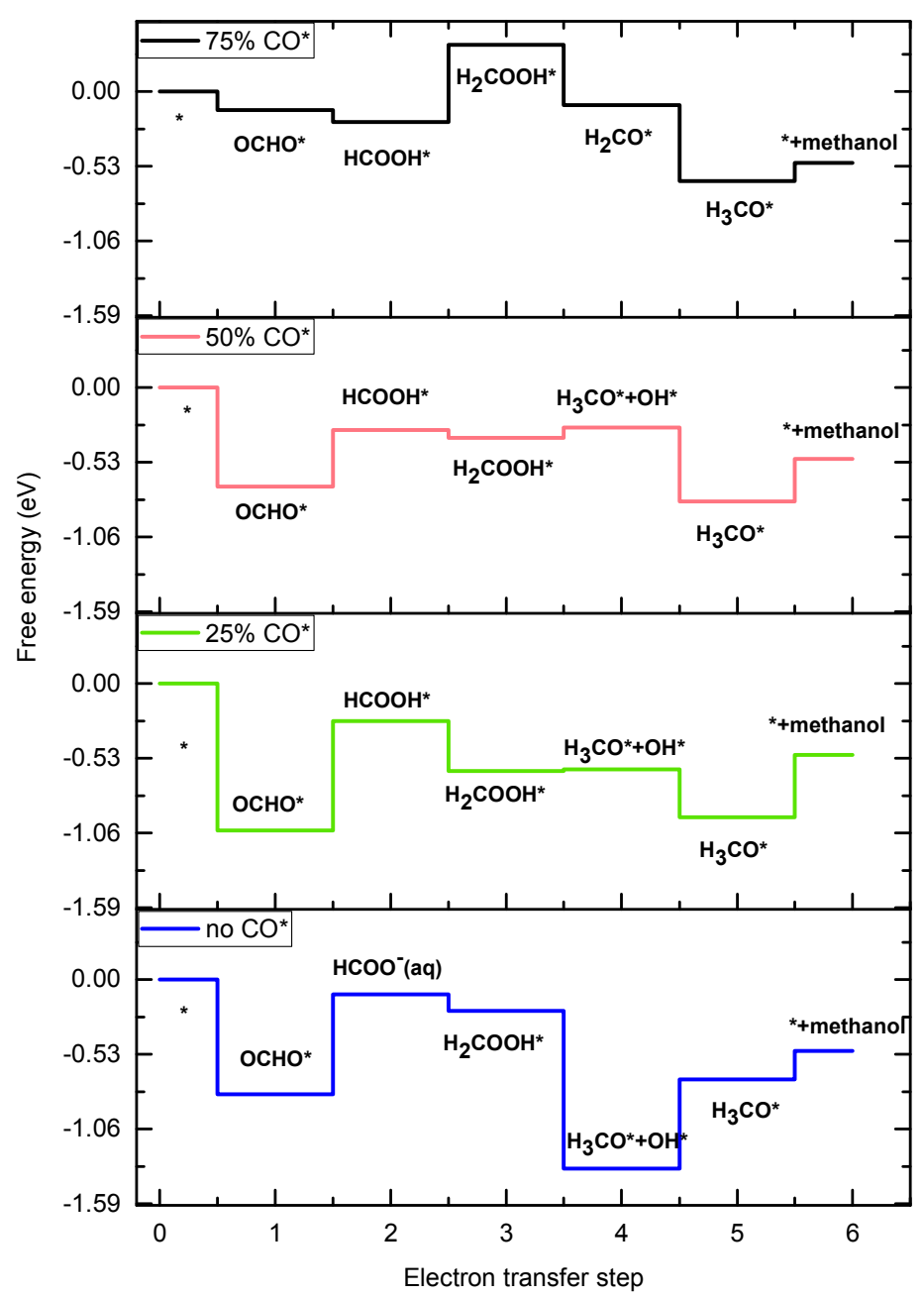

(a) 


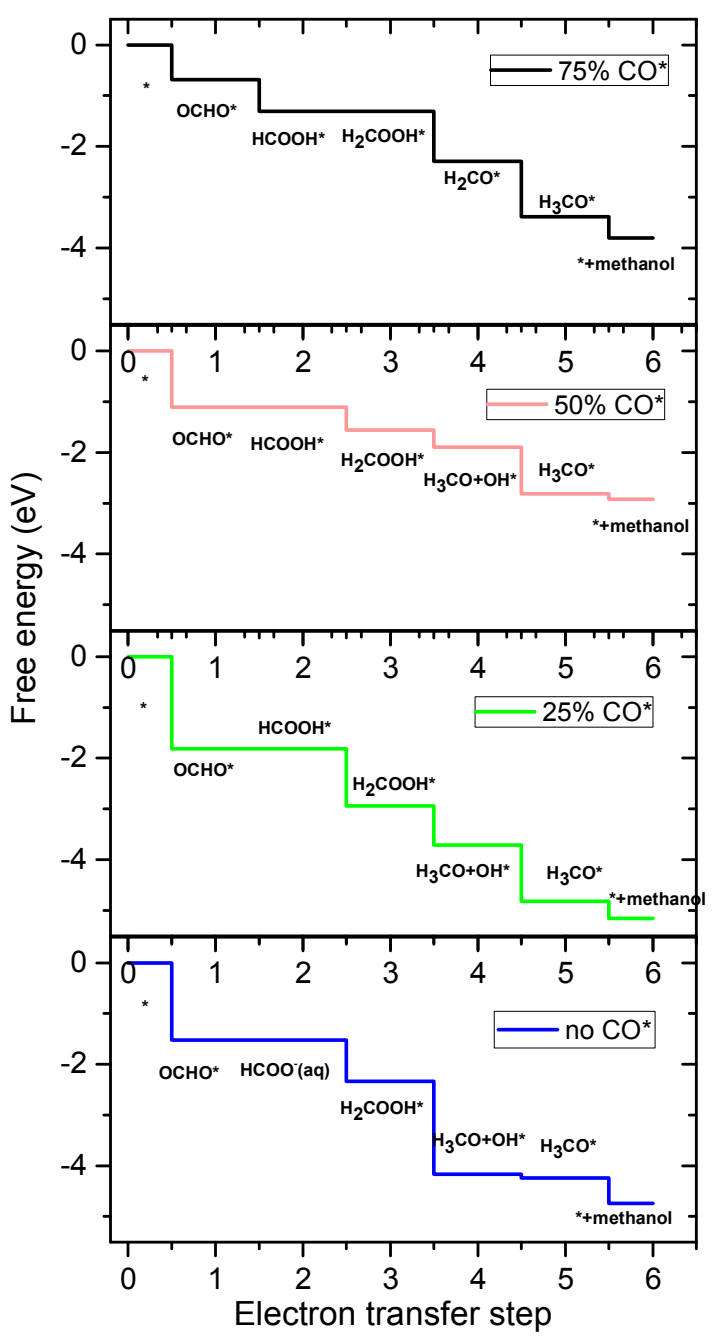

(b)

Figure 5: The thermodynamic path for methanol evolution at bridge site with $0 \%$, 25\%, 50\%, 75\% CO* spectator coverage at (a) $0 \mathrm{~V}-\mathrm{RHE}$ and (b) at the respective methanol onset potential of $-0.71,-0.78,-0.4,-0.55 \mathrm{~V}-\mathrm{RHE}$. A downward step signifies no reducing potential required for forward reaction and upward step mark need for proportional reducing potential for propelling the reaction step.

We proceed to consider formic acid in solution as a possible intermediate/product formed on $\mathrm{OCHO}^{*}$ activation (Figure 5). This step leads to either surface bound $\mathrm{HCOOH}^{*}$ or formic acid in solution. For $\mathrm{CO}^{*}$ coverages of up to $50 \%$, protonation of $\mathrm{OCHO}^{*}$ is energetically uphill (Figure $3(\mathrm{~b})$ and Figure 5(a)) forming $\mathrm{HCOOH}^{*}$ on $\mathrm{CO}^{*}$ covered surfaces and formic acid in the absence of $\mathrm{CO}^{*}$. This large increase in free energy requires a proportionately large reducing potential to be applied for the reaction to proceed. So $\mathrm{OCHO}^{*}$ formation can reduce the HER activity in the absence of $\mathrm{CO}^{*}$ simply by blocking the active sites as previously discussed. At $75 \%$ $\mathrm{CO}^{*}$ coverage, $\mathrm{OCHO}^{*}$ and $\mathrm{HCOOH}^{*}$ are both mono-dentate. The formation of 
$\mathrm{HCOOH}^{*}$ from $\mathrm{OCHO}^{*}$ is downhill in energy for $75 \%$ coverage (Figure 3(b)). Binding free energy of $\mathrm{HCOOH}^{*}$ w.r.t. solvated formic acid in liquid water is $\sim 0.1 \mathrm{eV}$, which is small enough for a large fraction of adsorbates to escape into solution instead of forming $\mathrm{HCOOH}^{*}$ (Figure 3(b)). Weakening of the $\mathrm{OCHO}^{*}$ adsorbate binding reduces the thermodynamic onset potential requirement to only $-0.02 \mathrm{~V}-\mathrm{RHE}$. Therefore, at this $\mathrm{CO}^{*}$ coverage, we expect a high turnover of formic acid at very low over potential, in good agreement with Spataru et. al. who observed this at only $0.13 \mathrm{~V}^{-\mathrm{RHE}^{11}}$ and $\mathrm{pH} 3.9$.

Investigations of the most probable methanol formation pathways at different $\mathrm{CO}^{*}$ coverage using free energy diagrams enables us to identify the electron transfer steps requiring large reducing potentials to go forward. The preferred pathway has been established to be as following for $\mathrm{CO}^{*}$ coverage $\leq 50 \%$.

$$
\begin{aligned}
& { }^{*}+\mathrm{CO}_{2}(\mathrm{aq})+\left(\mathrm{H}^{+}+\mathrm{e}^{-}\right) \rightarrow \mathrm{OCHO}^{*} \\
& \mathrm{OCHO}^{*}+\left(\mathrm{H}^{+}+\mathrm{e}^{-}\right) \rightarrow \mathrm{HCOOH}^{*} \text { or } \mathrm{OCHO}^{*}+\left(\mathrm{H}^{+}+\mathrm{e}^{-}\right) \rightarrow \mathrm{HCOO}^{-}(\mathrm{aq}) \\
& \mathrm{HCOOH}^{*}(\mathrm{aq})+\left(\mathrm{H}^{+}+\mathrm{e}^{-}\right) \rightarrow \mathrm{H}_{2} \mathrm{COOH}^{*} \text { or } \mathrm{HCOO}^{-}(\mathrm{aq})+\left(\mathrm{H}^{+}+\mathrm{e}^{-}\right) \rightarrow \mathrm{H}_{2} \mathrm{COOH}^{*} \\
& \mathrm{H}_{2} \mathrm{COOH}^{*}+\left(\mathrm{H}^{+}+\mathrm{e}^{-}\right) \rightarrow \mathrm{H}_{3} \mathrm{CO}^{*}+\mathrm{OH}^{*} \\
& \mathrm{H}_{3} \mathrm{CO}^{*}+\mathrm{OH}^{*}+\left(\mathrm{H}^{+}+\mathrm{e}^{-}\right) \rightarrow \mathrm{H}_{3} \mathrm{CO}^{*}+\mathrm{H}_{2} \mathrm{O}(\mathrm{I}) \\
& \mathrm{H}_{3} \mathrm{CO}^{*}+\left(\mathrm{H}^{+}+\mathrm{e}^{-}\right) \rightarrow \mathrm{H}_{3} \mathrm{COH}(\mathrm{aq})
\end{aligned}
$$

The lack of more than one active site for $75 \% \mathrm{CO}^{*}$ coverage forces the reaction pathway to go through $\mathrm{H}_{2} \mathrm{CO}^{*}$ instead of $\mathrm{H}_{3} \mathrm{CO}^{*}+\mathrm{OH}^{*}$ adsorbates (Figure 5).

$$
\begin{aligned}
& \mathrm{H}_{2} \mathrm{COOH}^{*}+\left(\mathrm{H}^{+}+\mathrm{e}^{-}\right) \rightarrow \mathrm{H}_{2} \mathrm{CO}^{*}+\mathrm{H}_{2} \mathrm{O}(\mathrm{I}) \\
& \mathrm{H}_{2} \mathrm{CO}^{*}+\left(\mathrm{H}^{+}+\mathrm{e}^{-}\right) \rightarrow \mathrm{H}_{3} \mathrm{CO}^{*}+\mathrm{H}_{2} \mathrm{O}(\mathrm{I})
\end{aligned}
$$

Formation of $\mathrm{OCHO}^{*}$ by $\mathrm{CO}_{2}$ protonation is downhill at $0 \mathrm{~V}$-RHE for all $\mathrm{CO}^{*}$ coverages. Reduction of the $\mathrm{H}_{2} \mathrm{COOH}^{*}$ intermediate (Figure 5 and Figure $4(\mathrm{a})$ ) is either downhill of slightly uphill $\left(0.07 \mathrm{eV}\right.$ for $50 \%$ bridge+cus $\mathrm{CO}^{*}$ coverage). Formation of $\mathrm{H}_{3} \mathrm{CO}^{*}$ is downhill, except in absence of any $\mathrm{CO}^{*}$ coverage. In the absence of any spectators, $\mathrm{H}_{3} \mathrm{CO}^{*}$ and $\mathrm{OH}^{*}$ can both occupy bridge sites. Stronger $\mathrm{OH}^{*}$ binding energies require a large reducing potential for removal. Overall, $\mathrm{OCHO}$ * activation for $0 \% \mathrm{CO}^{*}$ coverage $(0.71 \mathrm{eV}), 25 \% \mathrm{CO}^{*}$ coverage $(0.78 \mathrm{eV}), 50 \% \mathrm{CO}^{*}$ coverage $(0.4 \mathrm{eV})$ and $\mathrm{H}_{2} \mathrm{COOH}^{*}$ formation at $75 \% \mathrm{CO}^{*}$ coverage $(0.55 \mathrm{eV})$ are the thermodynamically most difficult steps (Figure $4(\mathrm{a})$ ). Thus application of a reducing potential same as the onset potential for these elementary steps automatically makes all other steps downhill as represented in Figure 4(b). 
Similar to the $\mathrm{OCHO}^{*}$ adsorbate, $\mathrm{H}_{2} \mathrm{COOH}^{*}$ is also bi-dentate when two contiguous bridge and cus sites are available (Figure $2(\mathrm{e}),(\mathrm{h})$ ); as is the case for $\mathrm{CO}^{*}$ coverages up to $50 \%$. Forcing $\mathrm{H}_{2} \mathrm{COOH}^{*}$ to be mono-dentate at $75 \% \mathrm{CO}^{*}$ coverage, makes it difficult (free energy increase of $0.6 \mathrm{eV}$ more than $50 \% \mathrm{CO}^{*}$ coverage) to reduce $\mathrm{HCOOH}^{*}$ forming $\mathrm{H}_{2} \mathrm{COOH}^{*}$ (Figure 5(a)). Consequently, this becomes the elementary proton transfer step, necessitating the most reducing potential. Due to interactions with spectating $\mathrm{CO}^{*}$, the stability of different intermediates change differently causing reaction step height (free energy change) to vary as well. The relative $\Delta G$ shift of these proton transfer step from intermediate binding energy variation due to $\mathrm{CO}^{*}$ spectator interaction is provided in Figure SI6. Changing the $\mathrm{CO}^{*}$ coverage modifies the potential needed to drive the elementary steps forward, but $\mathrm{OCHO}^{*}$ activation remians the most difficult step for $\mathrm{CO}^{*}$ coverage $50 \%$ or lower (Figure 5(a)).

$\mathrm{OH}^{*}$ removal is not a limitation for $\mathrm{CO} 2 \mathrm{RR}$ for any $\mathrm{CO}^{*}$ coverages, except $50 \%$ (Figure SI6), where $\mathrm{OH}^{*}$ removal needs a reducing potential $80 \mathrm{meV}$ lower than $\mathrm{OCHO}^{*}$ protonation. For $\mathrm{CO}^{*}$ spectator coverage of $25 \%$ to $75 \%$, methane and methanol evolution onset potential is close to $\mathrm{OH}^{*}$ removal potential (Figure 6). The magnitude of change in overall onset potential for methanol is not as abrupt as that observed for formic acid and hydrogen evolution (75\% coverage). Observable methanol evolution at different $\mathrm{CO}^{*}$ coverages will therefore be dependent on kinetic barriers and competition from hydrogen and formic acid evolution. For methane evolution, the favored pathway is identical to methanol evolution until the $5^{\text {th }}$ electron/proton transfer step, i.e. formation of $\mathrm{H}_{3} \mathrm{CO}^{*}$, at all $\mathrm{CO}^{*}$ coverages. At the $6^{\text {th }}$ step, methane is released by protonation on the carbon atom of the $\mathrm{H}_{3} \mathrm{CO}^{*}$ adsorbate, leaving an oxygen atom at the bridge site, which is eventually removed as water through two protonation steps. The thermodynamic limiting steps are identical to methanol evolution, except at $50 \%$ coverage, where the onset potential predicted of methane evolution from thermodynamic analysis is different from methanol (Figure 6). From $\mathrm{H}_{3} \mathrm{CO}^{*}$, methane evolution will be preferred if $\mathrm{C}-\mathrm{O}$ bond cleaving has a smaller barrier than detaching Ru-O bond.

Experimental evidence ${ }^{8,9}$ points to methanol formation having a smaller barrier, as methanol has been observed to be produced in much larger quantities than methane ${ }^{9-11}$. Popic et. al. observed up to $30.5 \%$ product efficiency for methanol at $-0.12 \mathrm{~V}-\mathrm{RHE}$, while no $\mathrm{CO}$ has been reported to be present. Conversely, Spataru et al. report excellent $\mathrm{HCOOH} / \mathrm{H}_{2}$ evolution with $\mathrm{CO}$ as minority product at similar potential on $\mathrm{RuO}_{2}$ electrode. These experimental results directly correlate to our conclusion that, moderate $\mathrm{CO}^{*}$ coverage aid in methanol evolution and high $\mathrm{CO}^{*}$ coverage leads to $\mathrm{HCOOH} / \mathrm{H}_{2}$ at very low potential.

Our simulation model does not explicitly consider $\mathrm{pH}$ effects. The discrepancy between observed and predicted methanol onset potential can originate from variations in $\mathrm{CO}^{*}$ coverage, $\mathrm{pH}$ effects or other differences like composition and 
surface structure. Preliminary work ${ }^{8}$ by Bandi suggested strong dependence of methanol evolution efficiency on $\mathrm{pH}$ and observed a much better methanol efficiency in acidic solution than neutral electrolyte. The concentration of methanol in the solvent can also affect the reaction thermodynamics of methanol production. With higher concentration, free energy of methanol increases and release of methanol from $\mathrm{H}_{3} \mathrm{CO}^{*}$ intermediate needs larger reducing potential.

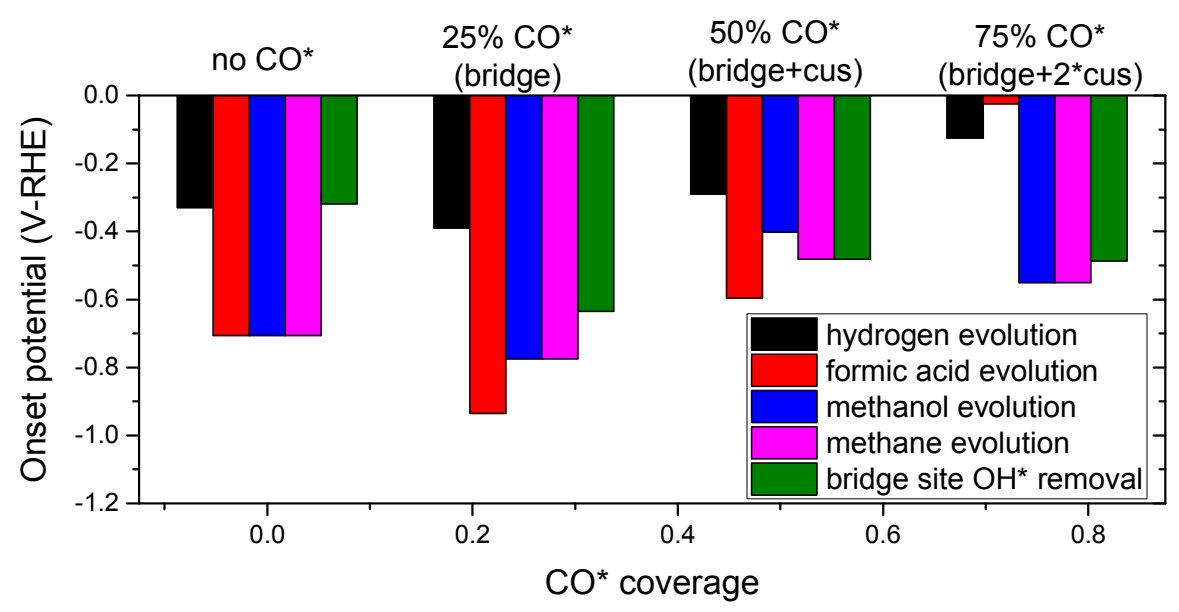

Figure 6: Onset potentials for hydrogen, formic acid, methanol, methane evolution at different $\mathrm{CO}^{*}$ spectator coverage. $\mathrm{OH}^{*}$ removal potential at bridge site included to provide information about possible $\mathrm{OH}^{*}$ blockage.

\section{Conclusions}

In summary, without $\mathrm{CO}^{*}$ coverage, $\mathrm{RuO}_{2}(110)$ is expected to start producing hydrogen via the cus sites $(-0.33 \mathrm{~V}-\mathrm{RHE})$ with hydroxylated bridge sites. Repulsive interactions with $\mathrm{CO}^{*}$ spectators destabilize $\mathrm{H}^{*}$. If the availability of $\mathrm{CO}_{2}$ in the reaction layer and the kinetic barriers for $\mathrm{CO}_{2}$ activation are not limiting, $\mathrm{OCHO}^{*}$ is preferred over $\mathrm{H}^{*}$ as the $1^{\text {st }}$ proton transfer product, as seen from a purely thermodynamic perspective. Transient formation of CO* from CO2RR leads to $25 \%$ to $75 \% \mathrm{CO}^{*}$ coverage. A large reducing potential is required to protonate stable bidentate $\mathrm{OCHO}^{*}$ and break one Ru-O bond at $0-50 \% \mathrm{CO}^{*}$ coverage. At $25 \% \mathrm{CO}^{*}$ coverage, methanol is expected to be the main CO2RR product, with an onset potential of $-0.78 \mathrm{~V}$ - $\mathrm{RHE}$ because $\mathrm{HCOOH}^{*}$ is surface bound. $50 \% \mathrm{CO}^{*}$ coverage is predicted to provide the best activity towards methanol formation. At this $\mathrm{CO}^{*}$ coverage, the HER cannot start above $-0.56 \mathrm{~V}$-RHE due to bridge site hydroxylation (Table 2) while methanol formation (onset of $-0.4 \mathrm{~V}$-RHE) is active at the $\mathrm{OH}^{*}$ removal potential $(-0.48 \mathrm{~V}-\mathrm{RHE})$. At a sufficient reducing potential, the CO2RR pathway to methanol is expected to show significant activity in conjunction with little hydrogen evolution for $25 \%-50 \% \mathrm{CO}^{*}$ coverage. The $75 \% \mathrm{CO}^{*}$ covered surface, on the contrary, have close to ideal onset potential for formic acid production, due to weakly bound mono-dentate $\mathrm{OCHO}^{*}$. Once $\mathrm{OH}^{*}$ is removed from the active site, both hydrogen and formic acid is expected to form. Suppression of HER at $50 \%$ or 
lower $\mathrm{CO}^{*}$ coverage by formation of $\mathrm{OCHO}^{*}$ at the active sites is critically dependent on fast reaction kinetics for $\mathrm{OCHO}^{*}$ formation. Good activity and selectivity obtained for $\mathrm{CO} 2 \mathrm{RR}$ on $\mathrm{RuO}_{2}$ catalysts are highly dependent on the $\mathrm{CO}^{*}$ coverage in the reaction environment. At high $\mathrm{CO}^{*}$ coverages $(75 \%)$, excellent availability of $\mathrm{CO}_{2}$ is critical for formic acid evolution. If, however, $\mathrm{CO}_{2}$ molecules are not readily available, hydrogen is expected to be the only observable product.

Binding energy alteration of both $\mathrm{H}^{*}$ and CO2RR intermediates emerging from adsorbate interaction with $\mathrm{CO}^{*}$ lets us observe switching of CO2RR/HER activity and CO2RR product selectivity at the optimal CO* coverage. $25 \%-50 \%$ CO* coverage is most conducive for methanol formation and higher $\mathrm{CO}^{*}$ coverage for formic acid evolution.

$\mathrm{RuO}_{2}$ based electrocatalysts have been shown experimentally to hold great promise for direct conversion of $\mathrm{CO}_{2}$ to methanol and formic acid. Based on this theoretical exploration, we show that $\mathrm{CO}^{*}$ spectators hold the key to good CO2RR activity and selectivity.

\section{Supporting Information}

Additional visualizations of and explanation for $\mathrm{CO}^{*}$ coverage configurations, adsorbate free energy diagrams, thermodynamic data for adsorbates and molecules, figure for methanol evolution elementary reaction step onset dependency on $\mathrm{CO}^{*}$ coverage, free energy of $\mathrm{CO}^{*}$ coverage configurations, visualization for all possible $\mathrm{CO}^{*}$ spectator models as well as atomic position data and visualization all catalyst surface simulations are provided.

\section{Acknowledgements}

Funding from the Lundbeck foundation (grant no. R141-2013-A13204) and The Velux Foundations through V-Sustain: The VILLUM Center for the Science of Sustainable Fuels and Chemicals (Grant no. 9455) are gratefully acknowledged. The Niflheim supercomputer at DTU was used for the computations performed in this work.

\section{References:}

(1) Chu, S.; Majumdar, A. Opportunities and Challenges for a Sustainable Energy Future. Nature 2012, 488 (7411), 294-303.

(2) Dunn, B.; Kamath, H.; Tarascon, J.-M. Electrical Energy Storage for the Grid: A Battery of Choices. Science (80-. ). 2011, 334 (6058), 928-935.

(3) Ganesh, I. Conversion of Carbon Dioxide into Methanol - A Potential Liquid Fuel: Fundamental Challenges and Opportunities (a Review). Renew. Sustain. 
Energy Rev. 2014, 31 (2014), 221-257.

(4) Hori, Y. Electrochemical CO2 Reduction on Metal Electrodes. In Modern Aspects of Electrochemistry; Springer New York: New York, NY, 2008; Vol. 42, pp 89-189.

(5) Kuhl, K. P.; Hatsukade, T.; Cave, E. R.; Abram, D. N.; Kibsgaard, J.; Jaramillo, T. F. Electrocatalytic Conversion of Carbon Dioxide to Methane and Methanol on Transition Metal Surfaces. J. Am. Chem. Soc. 2014, 136 (40), 1410714113.

(6) Peterson, A. A.; Abild-Pedersen, F.; Studt, F.; Rossmeisl, J.; Nørskov, J. K.; Lewis, N. S.; Nocera, D. G.; Hori, Y.; Kikuchi, K.; Murata, A.; et al. How Copper Catalyzes the Electroreduction of Carbon Dioxide into Hydrocarbon Fuels. Energy Environ. Sci. 2010, 3 (9), 1311-1315.

(7) Peterson, A. A.; Nørskov, J. K. Activity Descriptors for $\mathrm{CO}_{2}$ Electroreduction to Methane on Transition-Metal Catalysts. J. Phys. Chem. Lett. 2012, 3 (2), 251258.

(8) Bandi, A. Electrochemical Reduction of Carbon Dioxide on Conductive Metallic Oxides. J. Electrochem. Soc. 1990, 137 (7), 2157.

(9) Popic, J. P.; Avramov-Ivic, M. L.; Vukovic, N. B.; Popić, J.; Avramov-Ivić, M.; Vuković, N.; Popic, J. P.; Avramov-Ivic, M. L.; Vukovic, N. B.; Popić, J.; et al. Reduction of Carbon Dioxide on Ruthenium Oxide and Modified Ruthenium Oxide Electrodes in 0.5 M NaHCO 3. J. Electroanal. 1997, 421, 105-110.

(10) Qu, J.; Zhang, X.; Wang, Y.; Xie, C. Electrochemical Reduction of $\mathrm{CO}_{2}$ on $\mathrm{RuO}_{2} / \mathrm{TiO}_{2}$ Nanotubes Composite Modified Pt Electrode. Electrochim. Acta 2005, 50 (16-17), 3576-3580.

(11) Spataru, N.; Tokuhiro, K.; Terashima, C.; Rao, T. N.; Fujishima, A. Electrochemical Reduction of Carbon Dioxide at Ruthenium Dioxide Deposited on Boron-Doped Diamond. J. Appl. Electrochem. 2003, 33 (12), 1205-1210.

Rasul, S.; Anjum, D. H.; Jedidi, A.; Minenkov, Y.; Cavallo, L.; Takanabe, K. A Highly Selective Copper-Indium Bimetallic Electrocatalyst for the Electrochemical Reduction of Aqueous $\mathrm{CO}_{2}$ to CO. Angew. Chemie - Int. Ed. 2015, 54 (7), 2146-2150.

(13) Mistry, H.; Reske, R.; Zeng, Z.; Zhao, Z. J.; Greeley, J.; Strasser, P.; Cuenya, B. R. Exceptional Size-Dependent Activity Enhancement in the Electroreduction of $\mathrm{CO}_{2}$ over Au Nanoparticles. J. Am. Chem. Soc. 2014, 136 (47), 16473-16476.

(14) Li, Y.; Cui, F.; Ross, M. B.; Kim, D.; Sun, Y.; Yang, P. Structure-Sensitive $\mathrm{CO}_{2}$ Electroreduction to Hydrocarbons on Ultrathin Five-Fold Twinned Copper Nanowires. Nano Lett. 2017, 17 (2), 1312-1317.

(15) Varela, A. S.; Schlaup, C.; Jovanov, Z. P.; Malacrida, P.; Horch, S.; Stephens, I. E. L.; Chorkendorff, I. $\mathrm{CO}_{2}$ Electroreduction on Well-Defined Bimetallic 
Surfaces: Cu Overlayers on Pt(111) and Pt(211). J. Phys. Chem. C 2013, 117 (40), 20500-20508.

(16) Li, C. W.; Kanan, M. W. $\mathrm{CO}_{2}$ Reduction at Low Overpotential on Cu Electrodes Resulting from the Reduction of Thick $\mathrm{Cu}_{2} \mathrm{O}$ Films. J. Am. Chem. Soc. 2012, 134 (17), 7231-7234.

(17) Jovanov, Z. P.; Hansen, H. A.; Varela, A. S.; Malacrida, P.; Peterson, A. A.; Nørskov, J. K.; Stephens, I. E. L.; Chorkendorff, I. Opportunities and Challenges in the Electrocatalysis of $\mathrm{CO}_{2}$ and $\mathrm{CO}$ Reduction Using Bifunctional Surfaces: A Theoretical and Experimental Study of Au-Cd Alloys. J. Catal. 2016, 343, 215-231.

(18) Torelli, D. A.; Francis, S. A.; Crompton, J. C.; Javier, A.; Thompson, J. R.; Brunschwig, B. S.; Soriaga, M. P.; Lewis, N. S. Nickel-Gallium-Catalyzed Electrochemical Reduction of $\mathrm{CO}_{2}$ to Highly Reduced Products at Low Overpotentials. ACS Catal. 2016, 6 (3), 2100-2104.

(19) Karamad, M.; Hansen, H. A.; Rossmeisl, J.; Nørskov, J. K. Mechanistic Pathway in the Electrochemical Reduction of $\mathrm{CO}_{2}$ on $\mathrm{RuO}_{2}$. ACS Catal. 2015, 5 (7), 4075-4081.

(20) Bhowmik, A.; Vegge, T.; Hansen, H. A. Descriptors and Thermodynamic Limitations of Electrocatalytic Carbon Dioxide Reduction on Rutile Oxide Surfaces. ChemSusChem 2016, 9 (22), 3230-3243.

(21) Peterson, A. A.; Abild-Pedersen, F.; Studt, F.; Rossmeisl, J.; Nørskov, J. K.; Lewis, N. S.; Nocera, D. G.; Hori, Y.; Kikuchi, K.; Murata, A.; et al. How Copper Catalyzes the Electroreduction of Carbon Dioxide into Hydrocarbon Fuels. Energy Environ. Sci. 2010, 3 (9), 1311.

(22) Back, S.; Kim, H.; Jung, Y. Selective Heterogeneous $\mathrm{CO}_{2}$ Electroreduction to Methanol. ACS Catal. 2015, 5 (2), 965-971.

(23) An, W.; Xu, F.; Stacchiola, D.; Liu, P. Potassium-Induced Effect on the Structure and Chemical Activity of the $\mathrm{Cu}_{\mathrm{x}} \mathrm{O} / \mathrm{Cu}(1111)(X \leq 2)$ Surface: A Combined Scanning Tunneling Microscopy and Density Functional Theory Study. ChemCatChem 2015, 7 (23), 3865-3872.

(24) Cui, C.; Han, J.; Zhu, X.; Liu, X.; Wang, H.; Mei, D.; Ge, Q. Promotional Effect of Surface Hydroxyls on Electrochemical Reduction of $\mathrm{CO}_{2}$ over $\mathrm{SnO}_{\mathrm{x}} / \mathrm{Sn}$ Electrode. J. Catal. 2016, 343, 257-265.

(25) Marshall, S. T.; Medlin, J. W. Surface-Level Mechanistic Studies of Adsorbate adsorbate Interactions in Heterogeneous Catalysis by Metals. Surf. Sci. Rep. 2011, 66 (5), 173-184.

(26) Wang, H. Y.; Schneider, W. F. Comparative Chemistries of CO and NO Oxidation over $\mathrm{RuO}_{2}(110)$ : Insights from First-Principles Thermodynamics and Kinetics. Mol. Simul. 2012, 38 (8-9), 615-630.

(27) Tang, D. C.; Hwang, K. S.; Salmeron, M.; Somorjai, G. A. High Pressure 
Scanning Tunneling Microscopy Study of CO Poisoning of Ethylene Hydrogenation on $\mathrm{Pt}(111)$ and $\mathrm{Rh}(111)$ Single Crystals. J. Phys. Chem. B 2004, 108 (35), 13300-13306.

(28) Zhang, Y. J.; Sethuraman, V.; Michalsky, R.; Peterson, A. A. Competition between $\mathrm{CO}_{2}$ Reduction and $\mathrm{H}_{2}$ Evolution on Transition-Metal Electrocatalysts. ACS Catal. 2014, 4 (10), 3742-3748.

(29) Kresse, G. From Ultrasoft Pseudopotentials to the Projector Augmented-Wave Method. Phys. Rev. B 1999, 59 (3), 1758-1775.

(30) Kiejna, A.; Kresse, G.; Rogal, J.; De Sarkar, A.; Reuter, K.; Scheffler, M. Comparison of the Full-Potential and Frozen-Core Approximation Approaches to Density-Functional Calculations of Surfaces. Phys. Rev. B - Condens. Matter Mater. Phys. 2006, 73 (3), 6-9.

(31) Norskov, J. K.; Bligaard, T.; Rossmeisl, J.; Christensen, C. H. Towards the Computational Design of Solid Catalysts. Nat Chem 2009, 1 (1), 37-46.

(32) Wellendorff, J.; Lundgaard, K. T.; Møgelhøj, A.; Petzold, V.; Landis, D. D.; Nørskov, J. K.; Bligaard, T.; Jacobsen, K. W. Density Functionals for Surface Science: Exchange-Correlation Model Development with Bayesian Error Estimation. Phys. Rev. B - Condens. Matter Mater. Phys. 2012, 85 (23), 235149/1-23.

(33) Butler, S. R.; Gillson, J. L. Crystal Growth, Electrical Resistivity and Lattice Parameters of $\mathrm{RuO}_{2}$ and $\mathrm{IrO}_{2}$. Mater. Res. Bull. 1971, 6 (2), 81-89.

(34) Christensen, R.; Hansen, H. A.; Vegge, T. Identifying Systematic DFT Errors in Catalytic Reactions. Catal. Sci. Technol. 2015, 5 (11), 4946-4949.

(35) Hansen, H. A.; Shi, C.; Lausche, A.; Peterson, A.; Nørskov, J. K. Bifunctional Alloys for the Electroreduction of $\mathrm{CO}_{2}$ and $\mathrm{CO}$. Phys. Chem. Chem. Phys. 2016, 18 (111), 9194-9201.

(36) Nørskov, J. K.; Rossmeisl, J.; Logadottir, A.; Lindqvist, L.; Kitchin, J. R.; Bligaard, T.; Jónsson, H. Origin of the Overpotential for Oxygen Reduction at a Fuel-Cell Cathode. J. Phys. Chem. B 2004, 108 (46), 17886-17892.

(37) Reuter, K.; Scheffler, M. Composition and Structure of the $\mathrm{RuO}_{2}$ (110) Surface in an $\mathrm{O}_{2}$ and $\mathrm{CO}$ Environment: Implications for the Catalytic Formation of $\mathrm{CO}_{2}$ Karsten. Phys. Rev. B 2001, 65 (3), 045407/1-11. 
TOC Graphic

5 